\title{
How to do Better N400 Studies: Reproducibility, Consistency and Adherence to Research Standards in the Existing Literature
}

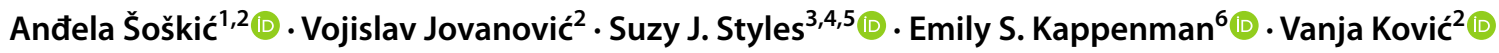

Received: 27 December 2019 / Accepted: 6 April 2021 / Published online: 9 August 2021

(c) The Author(s) 2021

\begin{abstract}
Given the complexity of ERP recording and processing pipeline, the resulting variability of methodological options, and the potential for these decisions to influence study outcomes, it is important to understand how ERP studies are conducted in practice and to what extent researchers are transparent about their data collection and analysis procedures. The review gives an overview of methodology reporting in a sample of 132 ERP papers, published between January 1980 - June 2018 in journals included in two large databases: Web of Science and PubMed. Because ERP methodology partly depends on the study design, we focused on a well-established component (the N400) in the most commonly assessed population (healthy neurotypical adults), in one of its most common modalities (visual images). The review provides insights into 73 properties of study design, data pre-processing, measurement, statistics, visualization of results, and references to supplemental information across studies within the same subfield. For each of the examined methodological decisions, the degree of consistency, clarity of reporting and deviations from the guidelines for best practice were examined. Overall, the results show that each study had a unique approach to ERP data recording, processing and analysis, and that at least some details were missing from all papers. In the review, we highlight the most common reporting omissions and deviations from established recommendations, as well as areas in which there was the least consistency. Additionally, we provide guidance for a priori selection of the N400 measurement window and electrode locations based on the results of previous studies.
\end{abstract}

Keywords ERP methodology $\cdot$ N400 $\cdot$ Pictures $\cdot$ Event related potentials $\cdot$ Open science $\cdot$ Reproducibility

\section{Introduction}

Anđela Šoškić

andjela.soskic@uf.bg.ac.rs

1 Teacher Education Faculty, University of Belgrade, Belgrade, Serbia

2 Laboratory for Neurocognition and Applied Cognition, Department of Psychology, Faculty of Philosophy, University of Belgrade, Belgrade, Serbia

3 Division of Psychology, School of Social Sciences, Nanyang Technological University, Singapore, Singapore

4 Centre for Research and Development On Learning (CRADLE), Nanyang Technological University, Singapore, Singapore

5 Singapore Institute for Clinical Sciences (SICS), A*Star Research Entities, Singapore, Singapore

6 Department of Psychology, San Diego State University, San Diego, CA, USA
Event-related potentials, or ERPs, are fluctuations in voltage that are associated in time with a physical or mental trigger (e.g., an external stimulus, a thought), and which can be recorded from the human scalp using electroencephalography (Picton et al., 2000). According to Luck (2014), ERPs were most likely first recorded in 1939 by Pauline and Hallowell Davis, who were investigating differences in the activity of the brain during wakefulness and sleep (Davis et al., 1939; Davis, 1939). Since those early days, ERP analysis has become a method of choice to answer a variety of questions about normal and pathological functioning of the human brain. The number of papers accumulated over the past decades is huge - for example, just a search for the exact phrase "event related potential*" on the Web of Science gave 26,047 results (on November 05, 2019), in fields ranging from psychiatry, immunology or even obstetrics, to psycholinguistics and educational psychology.

The rise in popularity of the method and its availability to laboratories across the world has increased the need 
for clear practice guidelines and standards that are widely available. The first guidelines for ERP recording were published in 1977, derived from the International Symposium on Cerebral Evoked Potentials in Man held in Brussels in 1974 (Donchin et al., 1977), updated by the Society for Psychophysiological Research in 2000 (Picton et al., 2000), and again in 2014 in a broader report focusing on electroencephalography as well as magnetoencephalography (Keil et al., 2014). In addition, specialized guidelines have been developed for fields that require a distinct approach, such as clinical studies (Duncan et al., 2009; Kappenman \& Luck, 2016) or experiments with children (Taylor \& Baldeweg, 2002), and ERP methodology papers have been published to provide guidelines for answering specific questions (e.g. Boudewyn et al., 2018; Delorme et al., 2007; Junghöfer et al., 1999; Kappenman \& Luck, 2010; Tanner et al., 2015). Methodology books on the ERP technique have also been published to help new researchers get acquainted with the basics and provide a more thorough overview (Handy, 2005; Luck, 2005, 2014).

These publications have provided useful guidance to researchers on how to make methodological decisions they encounter in ERP experiments. However, while basic standards outline what is not acceptable, there are still many decisions to make when recording and analysing ERP data, and for each of them, multiple options are acceptable. This necessarily puts a researcher in a dilemma over which way to go and opens a possibility of intentional or unintentional data manipulation in order to fit results to expectations.

An example of this issue is described in a recent paper by Luck and Gaspelin (2017), who demonstrated how "researcher degrees of freedom" could influence statistical analysis of ERP data. ERP recordings typically employ dozens of electrodes and result in hundreds of time points, which results in an almost unlimited variety of possible data analysis approaches, and, consequently, in the probability of a false significant finding approaching certainty.

These issues are not just a theoretical concern, as it has been demonstrated recently when a large collaborative preregistered replication attempt (Nieuwland et al., 2018) failed to support the key findings of an influential, widely cited study on the N400 in response to articles and nouns (DeLong et al., 2005). The study by Nieuwland et al. and ensuing commentaries (DeLong et al., 2017; Yan et al., 2017) do not only highlight the importance of careful design of new studies and replication attempts, but they also provide further evidence of the sensitivity of ERP analysis to subtle methodological decisions. Namely, Nieuwland et al. (2018) report that one of the issues raised after publishing a preprint of their paper was the difference in baseline duration between the original study by DeLong et al. (2005) and their replication attempt. The discrepancy in methods section resulted from omission of baseline information from the paper by DeLong et al., and it was corrected after communication between the two author teams following preprint publication. This example demonstrates the importance of ERP data analysis choices and comprehensive reporting on these choices.

The problem of researcher degrees of freedom is not unique to ERP methods - on the contrary, it has been recognized in other fields as well (Gelman \& Loken, 2013), and it is particularly concerning in studies involving abundance of data that can be treated in a multitude of ways (for a general discussion of the problems associated with researcher degrees of freedom, see Chambers, 2017). Neuroscience studies are especially prone to the problems of researcher degrees of freedom, due to the information-dense nature of the data collected, and the myriad of possible pre-processing pathways. For instance, one review of methods reporting in fMRI (Carp, 2012) has shown that there are almost as many analyses pipelines for fMRI data as there are individual studies, and many papers fail to provide sufficient information on methods to allow precise independent replications.

\section{Present Study}

Given this variability of methodological options, and the potential for them to influence study outcomes, it is important to understand how published ERP studies have been conducted in practice and to what extent researchers are transparent about their data collection and analysis procedures.

The aim of our paper is, thus, to provide a comprehensive overview of the present state of the field, as a platform from which to develop guidance for future neurocognitive research. The questions of interest are (1) how much methodological variability exists among studies investigating a wellestablished neurophysiological phenomenon, which would be expected to follow almost the same procedure, (2) which practices are the most prevalent, (3) how often researchers deviate from guidelines for good practice, (4) which deviations are the most common, (5) how often descriptions of methods and analyses are insufficiently detailed, and (6) which are the principal areas where improvements in reporting practices are necessary. Answering these questions allows us to provide evidence-based guidelines for making decisions about the analysis pipeline, for example, when a priori decisions are made based on previous research (e.g., choosing a reference site or the measurement time window). This overview also provides the opportunity to caution researchers against the most common deviations from best practices in ERP methodology and reporting.

Papers included in this review span over three decades, and many things have changed in the way ERP data is collected, processed, and analysed since then - new technologies and analyses have become available and we have 
learned new things both about ERP methodology and the N400 itself. This is reflected in changes between different versions of guidelines for good practice (Donchin et al., 1977; Keil et al., 2014; Picton et al., 2000). Therefore, the review also includes an insight into trends over time, to investigate how improvements in ERP methodology and recommendations were reflected in practice.

ERP study methods, pre-processing and analysis pathway depend to some extent on the study design, for example, on which components are being measured, the modality of the stimuli, and the population from which subjects are recruited. Given this variability, we chose to focus on a narrow category of ERP studies, those investigating a wellestablished component (the N400) in the most commonly assessed population (healthy neurotypical adults), in one of its most common modalities (visual images). The N400 is a negative-going wave peaking at about $400 \mathrm{~ms}$, whose amplitude is larger after presentation of a stimulus whose probability of occurrence is low within its semantic context (Kutas \& Federmeier, 2011). For example "He spread the warm bread with socks" would elicit a larger N400 than "He spread the warm bread with butter" (Kutas \& Hillyard, 1980). It is a well-known ERP component with a long history of successful conceptual replications (Kutas \& Federmeier, 2011), making it an ideal target for investigations of methodological and analytical coherence in the field. Thus, the findings of the review are directly relevant to a large group of N400 researchers, and some points also may generalize to other ERP components.

In order to provide the most robust dataset from which to draw conclusions, we conducted this survey of the existing literature in the form of a systematic review. The review provides an extensive insight into a variety of parameters, including properties of the study design (e.g., sample size), data pre-processing (e.g., filtering procedures), measurement (e.g., N400 time window), statistics (e.g., electrode sites in the ANOVA model), and, for more recent papers, references to supplemental information (e.g., raw data or analysis codes).

\section{Objective}

This systematic review documents the diversity of methodologies used, and clarity of reporting in peer-reviewed ERP papers, reporting an N400 to a visual image and recorded in adult healthy participants, published between January 1980 - June 2018 in journals included in two large databases: Web of Science and PubMed.

\section{Method}

Protocol of this study was not registered online, but we followed the Preferred Reporting Items for Systematic Reviews and Meta-Analyses (PRISMA) guidelines (Moher et al., 2009), where it was applicable. The PRISMA checklist for our review is available in Supplement 4 of the OSF repository for this article (Šoškić et al., 2021; see Supplementary materials for more information).

\section{Database Search}

The first step was to search online databases for papers relevant for this review. Two large aggregated databases were chosen: Web of Science and PubMed. These two databases contain a large sample of ERP studies, which is likely representative for the majority of peer-reviewed ERP literature.

Each database was searched using the following search terms: (N400 or ERP N4) AND (visual stimuli, visually evoked potentials, drawing(s), image(s), photo(graph-ies,y,s) or picture(s)). Default settings for search engines were used on both platforms including the search for key words in all fields and automatically generated MeSH (Medical Subject Headings) terms for PubMed, and search within Topic for the Web of Science. A list of exact search phrases with numbers of hits for each conducted search is available in the OSF repository for this article (Supplement 1). Search was limited to papers published after 1980, the year of the N400 discovery (Kutas \& Hillyard, 1980). It took place on 11th July 2018, and included papers published until 30th June 2018.

All references were merged into a single database using Mendeley Desktop (Mendeley Ltd.) to identify duplicate publications from the two sources.

\section{Article Scanning}

Following the PRISMA procedure, in order to identify which of the unique articles returned by the search did indeed contain an N400 study relevant for our review, we screened each article for possible inclusion. Two researchers independently conducted the screening, and where ambiguity or disagreement between the independent screeners arose, additional team members were asked to clarify or expand the initial criteria for eliminating studies.

The main criterion for selection was that the papers were original research papers on studies that included an ERP experiment with images as stimuli, and where the N400 following image onset was examined. Studies which included simultaneous presentation of information in various modalities or rapid presentation of visual image stimuli were not considered due to 
an effect of such designs on the N400 properties and analysis. For the same reason, papers were excluded if they involved any interventions or recording equipment which could affect experimental methodology or data analysis (e.g., tDCS, fMRI). Studies were selected for analysis only if participants were adults with no reported history of psychopathology.

On the other hand, we imposed no limitations regarding methods or treatment of outcome measures, since we focused on methodology, and not on results. We also included 15 studies that involved tasks with other types of target stimuli in addition to the task with visual images. Finally, there was no upper limit for participant age. The N400 is known to change linearly with age (Kutas \& Iragui, 1998), so any cut-off point would have been arbitrary. Furthermore, it was relatively common for studies in our sample to have at least one or two middle-aged participants. As a result of this decision, we included two aging studies with elderly participants. ${ }^{1}$

The review was limited to articles in English, since the majority of papers on ERPs are published in this language. However, studies conducted in other languages, but reported in English, were also included in the pool. Additionally, the focus of this review was on papers that had been verified and accepted by the scientific community via formal peer review. For this reason, we did not look for papers that were not published or at least in press at the time of the search. Furthermore, we checked all included papers for retractions and corrections. Conference proceedings were included in the pool if they were full-sized papers, whereas short resumes or abstracts were excluded due to the typical lack of methodological detail in the short format.

In addition, references were excluded if they could not be located through their journal or web search. Publications were considered duplications and duplicates were excluded if multiple papers had the same study design, sample characteristics, and same statistical results. In cases where papers, potentially or expressly, reported different analyses of the same data, all versions were included. Since we focused on methods, these papers added new information to our review, and they overlapped only in study design and pre-processing, which would likely have been the same if the authors had collected new data for each analysis.

\section{Data Extraction}

All papers were independently assessed by two researchers, who reported the results in separate spreadsheets. The two spreadsheets were then merged, and all diverging or unresolved points were jointly analysed by one of the authors working on papers assessment and a third team member.

\footnotetext{
${ }^{1}$ We compared the N400 measurement and analysis montage of aging studies and studies including targets in other modalities, but there were no discrepancies from the overall results.
}

When a conclusion about a reported item could not be reached due to conflicting, insufficient or ambiguous information, it was labelled as "inconclusive". In the case of some variables, categories could not be made in advance. In these cases, descriptions were logged and merged using the procedure above, and categorization was carried out post hoc by one team member.

Data was extracted for the following properties, using a total of 74 columns (variables):

- experimental design: design description, smallest sample size $^{2}$ - total and per group, smallest number of trials total and per situation, jittering pre-stimulus intervals, use of techniques to prevent overlap between the overt response and ERP window;

- equipment: hardware used for EEG recording (cap, amplifiers, other), software used during the experiment and data pre-processing and analysis (stimulus presentation, EEG acquisition, EEG/ERP pre-processing, statistics, other);

- data recording and pre-processing: reference used in data analyses, recording montage (active sites), scalp electrodes impedance, basic low-pass and high-pass online and offline filter settings (cut-off, roll-off, and cutoff type - half-amplitude or half-power), use of notch filters, number of trials left after trial rejection - what type of information was reported and what were the values, baseline length, epoch duration and whether it overlapped with an overt response or the beginning of the next trial, which artifacts were eliminated, artifact identification and elimination procedures, whether the order of operations could be assumed based on the description;

- measurement: N400 time window, and the reason for selecting this specific window, amplitude measure;

- statistical analyses and data presentation: which electrodes or electrode constellations were analysed (analysis montage), electrode analysis strategy (basis for choosing analysis montage), main analysis approach (e.g., ANOVA model), additional analyses (e.g., post hoc tests, topographical analyses), whether there was correction for sphericity violation and having multiple statistical tests, number of uncorrected (M)AN(C)OVAs, how many other components were analysed in addition to N400, which additional components were analysed and whether they were earlier or later than the $\mathrm{N} 400$, whether negative was plotted up or down in the graphs;

\footnotetext{
${ }^{2}$ In some cases, there was more than one experiment in a paper. Furthermore, individual experiments could have uneven groups or an uneven number of trials per condition. In these situations, we chose the lowest number, because we were interested in how often publications deviated from the guidelines for good practice.
} 
- about publications: publishing year, authors, whether it was a conference proceeding or a journal article;

- general: a column for additional data and comments.

Finally, availability of supplemental data (e.g., stimuli, raw data), identifiable through the article, was examined. This is a more recent trend in scientific reporting, and we did not expect most papers to provide this information. However, there has been a push in the past few years towards improving reproducibility and credibility of research through encouraging open science practices (Ioannidis et al., 2014; Nosek et al., 2015), so we were interested whether more recent papers had started to implement these recommendations.

Due to the volume of information, variable descriptions and coding details are provided in a separate file in Supplementary materials (Codebook-Supplement 3).

\section{Data Analysis}

The results were summarized by examining descriptive statistics. Frequencies of categorical variables, as well as means and standard deviations of numerical variables. In rare cases, where it was not possible or rational to categorize papers due to extreme variability, verbal descriptions were summarized by examining frequencies of key words.

Conveniently, 25 papers included in this review (18.9\%) were published between 1988-2000, when the first detailed guidelines for ERP research were published (Picton et al., 2000), and the same number of publications came out since 2015 , a year after presenting the latest version of the guidelines (Keil et al., 2014). We present a brief comparison of these two groups, to show how improvements in ERP methodology and recommendations were reflected in practice.

\section{Results and Discussion}

\section{Database Search and Article Selection}

In total, 1508 papers were returned by the searches. Two additional references were added, which were found during a preliminary stage of the systematic review, but they did not show up in database search results. After merging search results and removing duplicates, 790 titles remained.

Of these, 625 articles were excluded on inspection of title and abstract, and 33 were excluded after inspecting the full text. Alltogether, 17 of the papers which were excluded were in languages other than English,; three references were excluded because they could not be located through their journal or web search,; one paper was eliminated because it was a duplicate publication, 83 papers did not include an ERP
N400 experiment (e.g., theory papers, intracranial recordings), others were rejected based on their methods (sample or study design). As a result, 132 papers survived the exclusion criteria.

There were no retractions, and only one correction (concerning a name spelling error). Six conference proceedings were included in our review, and the remaining articles were peer-reviewed journal articles.

The PRISMA flow diagram summarizing articles included or excluded at the different stages of screening can be seen in Fig. 1. Supplement 2a contains libraries with references found by searching PubMed and Web of Science. The full list of all papers included in this report can be found in Table 1, and a library with all references selected for analysis is available in Supplement $2 b$. Supplement 5 contains the spreadsheet with extracted information on individual papers, while Supplement $6 a, b, c, d$ contains files with all analyses and graphs presented here.

\section{The Big Picture}

\section{How Often are Descriptions of Methods and Analyses Insufficiently Detailed? Which are the Principal Areas Where Improvements in Reporting Practices are Necessary?}

It would not be difficult to guess which were the most frequently described aspects of the reviewed studies. Sample size, ${ }^{3}$ number of presented trials, and amplitude measurement window, types of statistical analyses (e.g., ANOVA) were reported universally or almost universally, with only a few exceptions.

Similarly, amplitude measure was reported in $93.2 \%$ of papers, and the analysis montage could be extracted from $88.6 \%$ of all papers. These numbers are high, but still concerning, given that these are some of the most important aspects of a study.

At the next level of clarity, there were methodology decisions which were described in the majority of papers, but there was still a considerable number of papers in which this information was either missing or not adequately described. First, information about the reference used for data analysis was provided in $80.3 \%$ of all papers. The most frequent issue with reporting on the voltage reference was not providing a description of the recording montage when using the average reference, although, in some cases, details about a mastoid or earlobe

\footnotetext{
${ }^{3}$ One point that the $\mathrm{N} 400$ researchers may want to pay attention to in the future is reporting on excluded participants. In a handful of cases, the sample description did not allow determining whether the sample size was given with or without excluded participants.
} 


\section{PRISMA 2009 Flow Diagram}
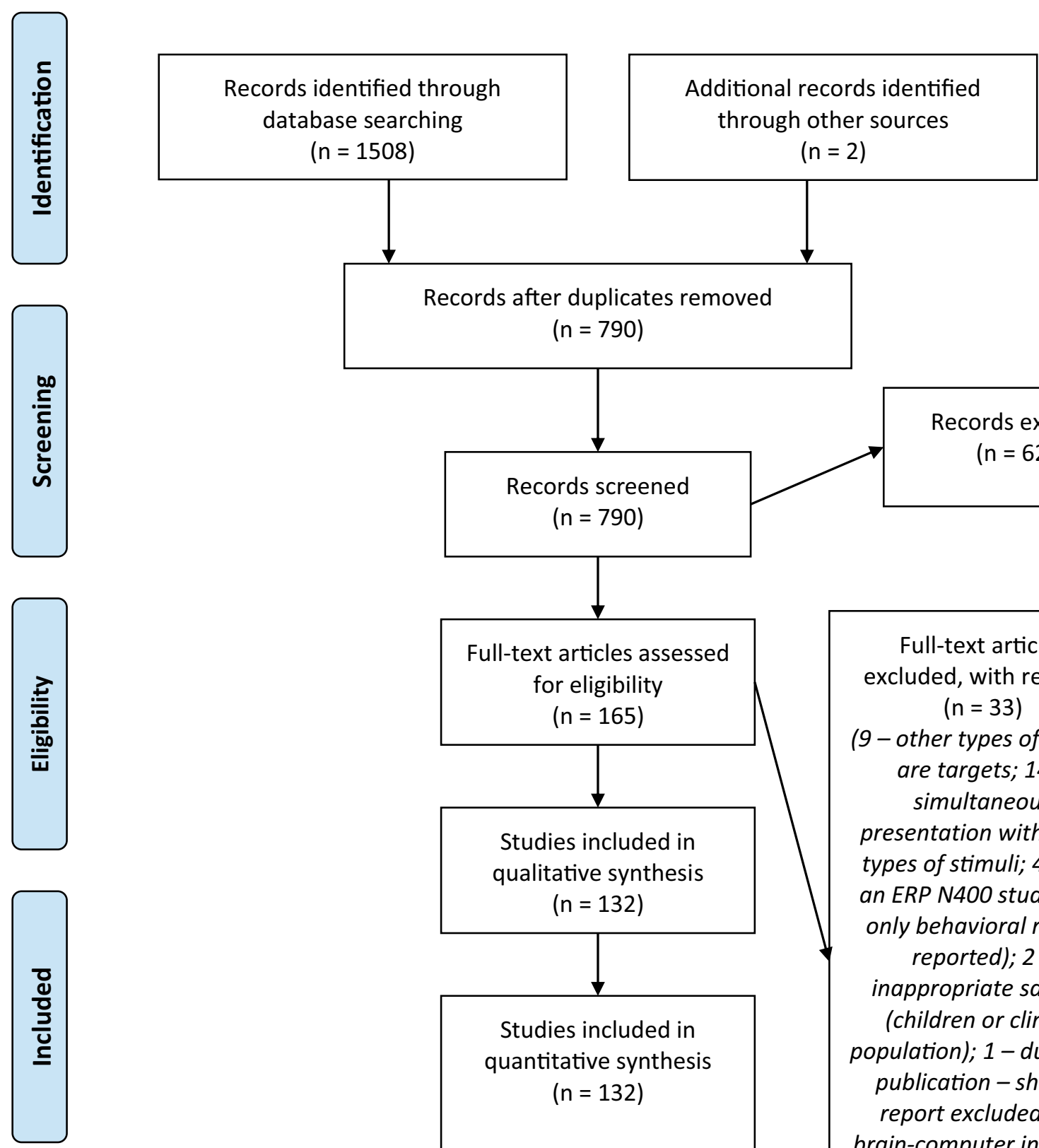

Records after duplicates removed

$$
(n=790)
$$
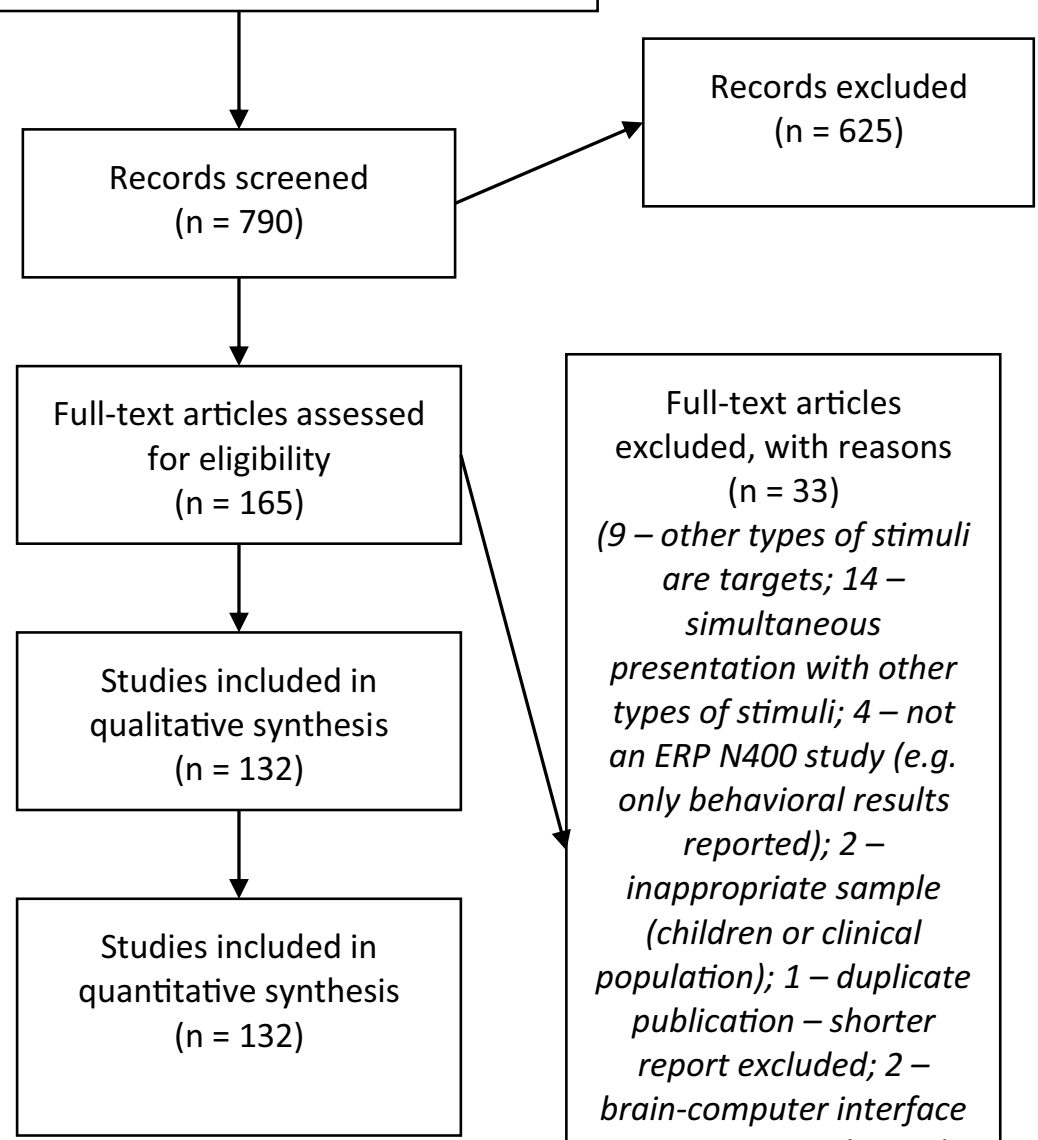

Full-text articles excluded, with reasons

$$
(n=33)
$$

(9-other types of stimuli are targets; 14 simultaneous presentation with other types of stimuli; 4-not an ERP N400 study (e.g. only behavioral results reported); 2 inappropriate sample (children or clinical population); 1 - duplicate publication - shorter report excluded; 2 brain-computer interface experiment with rapid presentation of stimuli)

From: Moher D, Liberati A, Tetzlaff J, Altman DG, The PRISMA Group (2009). Preferred Reporting /tems for Systematic Reviews and MetaAnalyses: The PRISMA Statement. PLoS Med 6(7): e1000097. doi:10.1371/journal.pmed1000097

For more information, visit www.prisma-statement.org. 
४Fig. 1 PRISMA flow diagram

reference were omitted, too. While omitting details about the mastoid reference can be relatively benign, the average reference can differ a lot depending on the recording montage (Luck, 2005, 2014), and it may even be inappropriate to use it depending on the recording montage size and electrode locations (Junghöfer et al., 1999; Keil et al., 2014; Picton et al., 2000). Additionally, in some papers, it was difficult to assess whether the term "linked reference" referred to physical linking or averaging. Similarly, baseline duration was explicitly described in $77.3 \%$ of papers. Some of the papers which did not contain baseline duration information, included reports on prestimulus period duration, but the two may not necessarily be the same, and they were not the same in other papers included in this review. Additionally, we did not quantify frequencies of issues related to graphical representation of ERPs, but it is noteworthy that in some papers, baseline period was not shown in graphs, either in its entire duration or at all. Epoch durations were provided slightly more often, in $83.3 \%$ of all cases. It was similar with reporting impedances for low input-impedance amplifiers (84.0\%), but descriptions of data quality obtained by high-input impedance amplifiers were provided only in four out of ten papers (42.9\%). Amplifier manufacturer and recording montage were both provided in $59.8 \%$ of cases. The latter was in some cases completely left out from the reports, but other papers were labelled inconclusive because of conflicting information, usually between figure, electrode list and electrode count. Recording montages often have dozens of electrodes, which can make errors easy to overlook, so future researchers may want to make sure to double-check whether all information is correct and consistent. Almost a third of all papers $(28.0 \%)$ did not describe the methods for eliminating artifacts beyond specifying whether they were removed using correction or rejection. Even when more details were given, they were not always sufficient to evaluate and replicate the procedure. Important decisions about data analysis - selection of time window(s) and electrode locations for the main statistical analysis - were not justified in about a third of all cases (34.0\% and 36.3\%, respectively). Moreover, when previous literature was cited as the sole basis for these decisions, in about half of all cases $(47.8 \%)$, they were not supported by the cited papers. In addition, various details about the analyses applied to these time windows and electrodes were inconclusive in $4-17 \%$ of papers. In some of these cases, some information was omitted, but, in others, there was conflicting information between Methods and Results sections. One possible cause of this discrepancy could be the peer review process. Therefore, future researchers may want to check whether the appropriate changes were made in all parts of the text if a different approach is taken after feedback from reviewers.

Finally, there were aspects of the examined studies which were rarely adequately described, and which warrant urgent attention of researchers and reviewers. When it comes to the number of trials per condition which were averaged together, $13.64 \%$ papers reported the average number or percentage of rejections for each condition, along with the range of trial counts or at least the threshold for excluding a participant, while $40.2 \%$ publications had no information on the number of trials which was left after rejection due to artifacts and/or behavioural errors. Reports on digital and especially analog filters frequently specified only their cut-off frequencies (54.1-96.2\% of cases for different filters), and even the cut-off was described without specifying whether it represents halfamplitude or half-power point in the frequency response function in $78.8 \%$ papers. A reconstruction of the order of pre-processing and measurement steps could be made in $46.2 \%$ of all cases, and in many of these cases, it was only an assumption based on the order in which the operations were described. Three common issues can be noted (1) in some papers, the new reference after re-referencing was specified in the recording section together with online reference, (2) a pre-processing step that had likely taken place (e.g. artifact removal) was not mentioned in the paper, so a reader could not be sure if it had taken place and at which stage, (3) the last step, averaging, was described first, in a sentence in which several other steps were mentioned as side points, in a way that made it impossible to tell at which moment they were applied. Finally, we did not quantify this, but it was not possible to determine how many comparisons were made in total in some of the studies.

To summarize all variables, 61 papers $(46.21 \%)$ were categorized as inconclusive or contained details labeled as inconclusive on variables containing verbal descriptions. In addition, at least some details were omitted from all papers. However, even when filter properties other than cut-off, equipment, and software (the most commonly omitted items) were not taken into account, there were only two studies in which all other information was provided (conducted by Cansino et al. (2012) and by Federmeier \& Kutas (2002)).

This information is graphically summarized in Fig. 2. The figure shows percentages of papers in which (1) the methodological information in question was provided, (2) some information was given, but it was either partial or inconclusive, or (3) the detail in question was omitted. For more details about Fig. 2, see Supplement 6d. 
Table 1 Papers evaluated in this report, in chronological order by year and alphabetical order within a year

\begin{tabular}{|c|c|c|}
\hline No & Decade & Study \\
\hline 1 & $1980 \mathrm{~s}$ & (Barrett et al., 1988) \\
\hline 2 & & (Barrett \& Rugg, 1989) \\
\hline 3 & $1990 \mathrm{~s}$ & (Barrett \& Rugg, 1990) \\
\hline 4 & & (Friedman, 1990) \\
\hline 5 & & (Nigam et al., 1992) \\
\hline 6 & & (Stuss et al., 1992) \\
\hline 7 & & (Bobes et al., 1994) \\
\hline 8 & & (Holcomb \& McPherson, 1994) \\
\hline 9 & & (Perez-Abalo et al., 1994) \\
\hline 10 & & (Pratarelli, 1994) \\
\hline 11 & & (Nielsen-Bohlman \& Knight, 1995) \\
\hline 12 & & (Schweinberger et al., 1995) \\
\hline 13 & & (Yano, 1995) \\
\hline 14 & & (Debruille et al., 1996) \\
\hline 15 & & (Ganis et al., 1996) \\
\hline 16 & & (Pietrowsky et al., 1996) \\
\hline 17 & & (Simos \& Molfese, 1997) \\
\hline 18 & & (Mecklinger, 1998) \\
\hline 19 & & (Münte et al., 1998) \\
\hline 20 & & (Grigor, 1999) \\
\hline 21 & & (Jordan \& Thomas, 1999) \\
\hline 22 & & (McPherson \& Holcomb, 1999) \\
\hline 23 & & (Olivares et al., 1999) \\
\hline 24 & $2000 \mathrm{~s}$ & (Castle et al., 2000) \\
\hline 25 & & (Eimer, 2000) \\
\hline 26 & & (Kiefer, 2001) \\
\hline 27 & & (Bensafi et al., 2002) \\
\hline 28 & & (Federmeier \& Kutas, 2002) \\
\hline 29 & & (Hamm et al., 2002) \\
\hline 30 & & (West \& Holcomb, 2002) \\
\hline 31 & & (Ganis \& Kutas, 2003) \\
\hline 32 & & (Jemel et al., 2003) \\
\hline 33 & & (Mnatsakanian \& Tarkka, 2003) \\
\hline 34 & & (Olivares et al., 2003) \\
\hline 35 & & (Schendan \& Kutas, 2003) \\
\hline 36 & & (Wang et al., 2003) \\
\hline 37 & & (Wicha, et al., 2003a, 2003b) \\
\hline 38 & & (Wicha, et al., 2003a, 2003b) \\
\hline 39 & & (Gunter \& Bach, 2004) \\
\hline 40 & & (Mnatsakanian \& Tarkka, 2004) \\
\hline 41 & & (Trenner et al., 2004) \\
\hline 42 & & (Wang et al., 2004) \\
\hline 43 & & (Yovel \& Paller, 2004) \\
\hline 44 & & (Balconi \& Pozzoli, 2005) \\
\hline 45 & & (Gierych et al., 2005) \\
\hline 46 & & (Supp et al., 2005) \\
\hline 47 & & (Eddy et al., 2006) \\
\hline 48 & & (Paz-Caballero et al., 2006) \\
\hline 49 & & (Cooper et al., 2007) \\
\hline
\end{tabular}

Table 1 (continued)

\begin{tabular}{|c|c|c|}
\hline No & Decade & Study \\
\hline 50 & & (Mao \& Wang, 2007) \\
\hline 51 & & (Proverbio et al., 2007) \\
\hline 52 & & (Wu \& Coulson, 2007) \\
\hline 53 & & (Boldini et al., 2008) \\
\hline 54 & & (Hirschfeld et al., 2008) \\
\hline 55 & & (Koester \& Schiller, 2008) \\
\hline 56 & & (Lüdtke et al., 2008) \\
\hline 57 & & (Neumann \& Schweinberger, 2008) \\
\hline 58 & & (Ortega et al., 2008) \\
\hline 59 & & (Steffensen et al., 2008) \\
\hline 60 & & (Zhang et al., 2008) \\
\hline 61 & & (Eddy \& Holcomb, 2009) \\
\hline 62 & & (Harris et al., 2009) \\
\hline 63 & & (Kovic et al., 2009) \\
\hline 64 & & (Proverbio \& Riva, 2009) \\
\hline 65 & & (Shibata et al., 2009) \\
\hline 66 & $2010 \mathrm{~s}$ & (Eddy \& Holcomb, 2010) \\
\hline 67 & & (Khateb et al., 2010) \\
\hline 68 & & (Liu et al., 2010) \\
\hline 69 & & (Lu et al., 2010) \\
\hline 70 & & (Mudrik et al., 2010) \\
\hline 71 & & (Olivares \& Iglesias, 2010) \\
\hline 72 & & (Proverbio et al., 2010) \\
\hline 73 & & (Saavedra et al., 2010) \\
\hline 74 & & (Eddy \& Holcomb, 2011) \\
\hline 75 & & (Herring et al., 2011) \\
\hline 76 & & (Huffmeijer et al., 2011) \\
\hline 77 & & (Kiefer et al., 2011) \\
\hline 78 & & (Kuipers \& Thierry, 2011) \\
\hline 79 & & (Liao et al., 2011) \\
\hline 80 & & (Lin et al., 2011) \\
\hline 81 & & (Maillard et al., 2011) \\
\hline 82 & & (Wu \& Coulson, 2011) \\
\hline 83 & & (Yum et al., 2011) \\
\hline 84 & & (Blackford et al., 2012) \\
\hline 85 & & (Bramão et al., 2012) \\
\hline 86 & & (Cansino et al., 2012) \\
\hline 87 & & (Cohn et al., 2012) \\
\hline 88 & & (Demiral et al., 2012) \\
\hline 89 & & (Hirschfeld et al., 2012) \\
\hline 90 & & (Kovalenko et al., 2012) \\
\hline 91 & & (Schendan \& Ganis, 2012) \\
\hline 92 & & (Butler et al., 2013) \\
\hline 93 & & (Diéguez-Risco et al., 2013) \\
\hline 94 & & (Giglio et al., 2013) \\
\hline 95 & & (Olivares et al., 2013) \\
\hline 96 & & (Proverbio et al., 2013) \\
\hline 97 & & (Riby \& Orme, 2013) \\
\hline 98 & & (Võ \& Wolfe, 2013) \\
\hline 99 & & (Baetens et al., 2014) \\
\hline
\end{tabular}


Table 1 (continued)

\begin{tabular}{|c|c|c|}
\hline No & Decade & Study \\
\hline 100 & & (Balconi \& Vitaloni, 2014) \\
\hline 101 & & (Boutonnet et al., 2014) \\
\hline 102 & & (Lensink et al., 2014) \\
\hline 103 & & (Li \& Lu, 2014) \\
\hline 104 & & (Manfredi et al., 2014) \\
\hline 105 & & (Mudrik et al., 2014) \\
\hline 106 & & (Proverbio et al., 2014) \\
\hline 107 & & (Schleepen et al., 2014) \\
\hline 108 & & (Dominguez-Martinez et al., 2015) \\
\hline 109 & & (Dyck \& Brodeur, 2015) \\
\hline 110 & & (Gao et al., 2015) \\
\hline 111 & & (Kaczer et al., 2015) \\
\hline 112 & & (Khushaba et al., 2015) \\
\hline 113 & & (Küper et al., 2015) \\
\hline 114 & & (Maffongelli et al., 2015) \\
\hline 115 & & (Ousterhout, 2015) \\
\hline 116 & & (Proverbio et al., 2015) \\
\hline 117 & & (Schendan \& Ganis, 2015) \\
\hline 118 & & (Zani et al., 2015) \\
\hline 119 & & (Zhou et al., 2015) \\
\hline 120 & & (Hoogeveen et al., 2016) \\
\hline 121 & & (Niu et al., 2016) \\
\hline 122 & & (Rojas et al., 2016) \\
\hline 123 & & (Yinan Wang \& Zhang, 2016) \\
\hline 124 & & (Gui et al., 2017) \\
\hline 125 & & (Kiefer et al., 2017) \\
\hline 126 & & (Mandikal Vasuki et al., 2017) \\
\hline 127 & & (Ortiz et al., 2017) \\
\hline 128 & & (Pergola et al., 2017) \\
\hline 129 & & (Savic et al., 2017) \\
\hline 130 & & (Wang et al., 2017) \\
\hline 131 & & (Bouten et al., 2018) \\
\hline 132 & & (Yi et al., 2018) \\
\hline
\end{tabular}

Aside from the report itself, little supplementary material was identifiable through analysed papers, even for more recent studies. Most papers (86.4\%) did not refer to accessible supplementary materials other than reports on additional analyses. Admittedly, in one of them, readers were informed that data was stored on a departmental server and could be accessed by contacting authors or the department, while another paper provided a link to a Harvard Dataverse page, albeit locked to website visitors even after registration. Additionally, 9.8\% papers provided only lists of stimuli descriptions, and another $2.3 \%$ provided actual stimuli or information needed to identify them in published databases of images. There were, in fact, only two papers in which access to ERP data had been provided - a link to behavioural and raw ERP data in one paper, and to component mean amplitudes in the other. There were no studies with published codes for stimulus presenting, ERP data preprocessing or analyses. To provide supplementary information has become both possible and advocated (through Open Access initiatives) only recently, so high availability in the entire sample of papers cannot be expected. The question of supplement availability in the more recent studies is covered in the section Trends over time.

\section{How Much Variability is There Among Studies that Would be Expected to Follow Similar Procedures, Because They All Investigate the Same Well-Established Neurophysiological Phenomenon? Which Practices are the Most Prevalent?}

While Fig. 2 presented how many papers reported on different methodological decisions, Fig. 3 shows frequency of each option for a given methodological decision, when this information was available.

There were several points on which the majority of researchers took the same approach. The decision which was present in the largest majority of papers was that main effects and interactions were treated as a priori comparisons, and thus not subjected to correction for multiple comparisons (more than $95 \%$ of all papers), despite the number of comparisons which were made in most studies. Next, in approximately nine out of ten papers, ANOVA was the statistical analysis of choice. Notch filters were avoided in nine out of ten papers, as well. When low-impedance amplifiers were used, authors reported lowering impedances below $5 \mathrm{k} \Omega$ in $73.8 \%$ studies and even lower in additional $4.7 \%$ papers (78.5\% in total). Out of 64 papers which provided maps of topographic distribution of ERPs, $78.1 \%$ opted for the most common option - voltage maps. Mean amplitude (calculated from single and difference waves) and variations of the mean mastoid/earlobe reference were used in three quarters of papers. The latter is especially relevant to future researchers who want to present their data in a way comparable to the previously conducted studies. If average or other less frequent references are used, the future researchers may want to include at least plots based on mean mastoid/ earlobe reference, too, to enhance comparability with previous research (Picton et al., 2000). In a total of $70.0 \%$ of papers, authors reported testing for sphericity and applying corrections where necessary, and $80.5 \%$ of them used the more conservative Greenhouse-Geisser adjustment (1959). When it comes to trial design, seven out of ten studies did not rely on stimulus timing jittering $(71.1 \%)$ or measures to prevent overlap between motor response and ERP components (52.3\%), to reduce sources of noise in ERP recordings. Examples of measures used to prevent overlap between motor response and ERP components included a cue for participants to respond only after the ERP time window had passed (which is efficient only if combined with jittering the cue because of preparatory motor activity) and designs 
Fig. 2 Frequencies of omitting methodological details from reports. The $y$ axis shows methodological information that was examined, while the $x$ axis shows the percentage of papers in which this information was provided, partly provided, or not provided. All percentages are relative to No - the number of cases relevant for the variable in question (e.g., studies in which a procedure was used). Green bars show percentage of papers in which the methodological information in question was provided. Yellow bars show percentages of papers in which some information was given, but it was either partial or inconclusive. Red bars show percentages of papers from which the detail in question was omitted. Table of frequencies and more details on them can be found in Supplement 6d

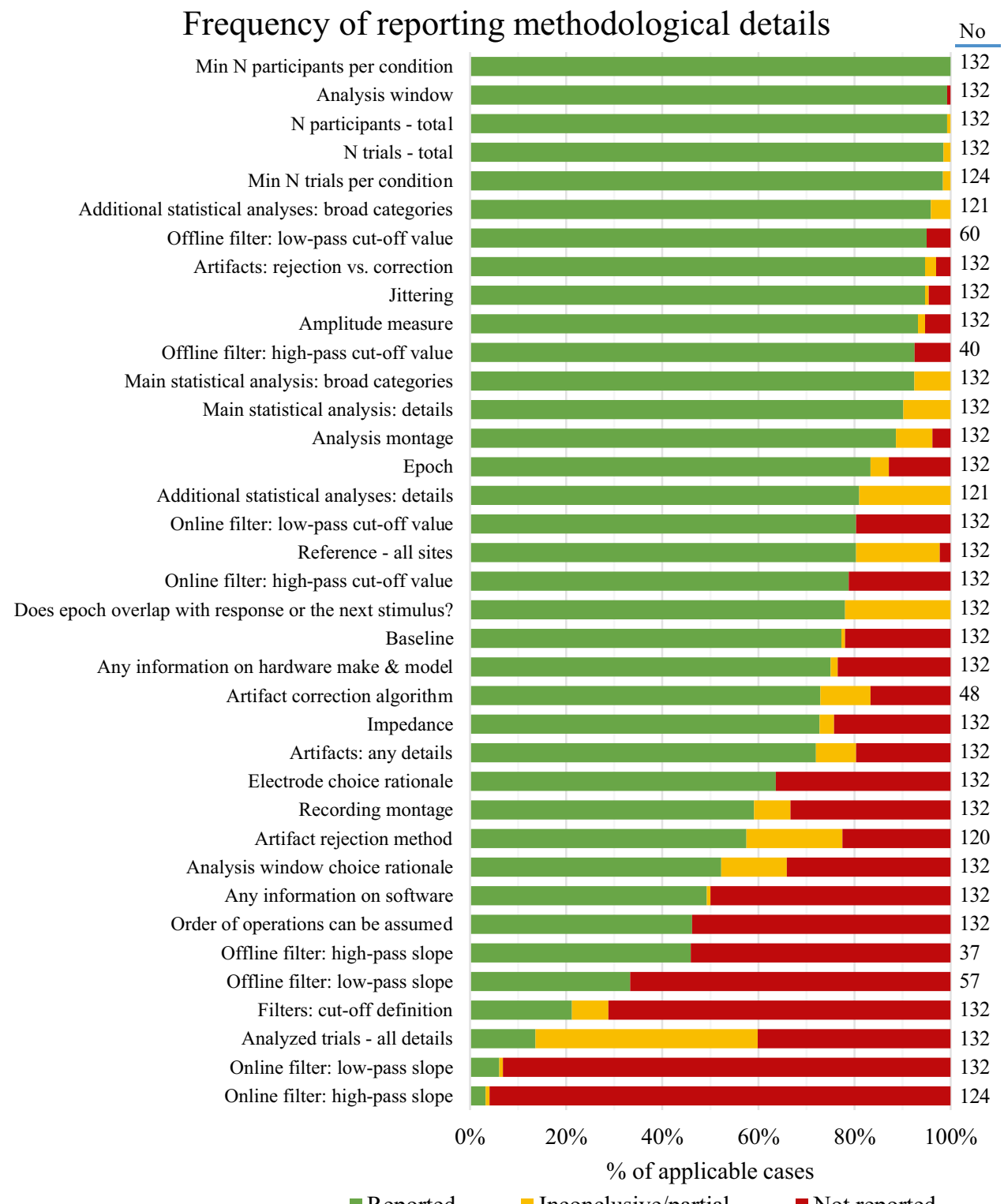

$\square$ Reported $\quad$ Inconclusive/partial $\quad$ Not reported in which there was no overt response to stimuli used in the N400 analyses, either because overt responding was not required or because the participants responded to other stimuli. When it comes to artifact elimination method, $62.4 \%$ papers reported rejecting all types of artifacts which were detected. Analyses based on LORETA were most frequently used to estimate sources of ERP components, although three distinct types of LORETA analysis were found (LORETA, sLORETA, swLORETA, used in 16.0-20.0\% localisation analyses).

The next group of methodological decisions were the ones on which the reviewed publications diverged, but the number of options was moderate and at least some common options could be identified. Such decisions were equipment manufacturer (12 and 18 manufacturers with $34.8 \%$ and $24.4 \%$ share for the main option for cap and amplifiers, respectively), software used in different stages from stimulus presentation to statistical analysis (between 8-17 options, and $20.8-50.0 \%$ share for the main option), baseline (11 different baselines, but $100 \mathrm{~ms}$ was used in $43.1 \%$ of all cases), high-pass and low-pass filter cut-offs (9-18 different cut-offs, but 0.1 and $30 \mathrm{~Hz}$ were the most frequent; note that digital high-pass and low-pass filters were used in $28.7 \%$ and $44.2 \%$ of publications, respectively), time window selection strategy (11 strategies, out of which visual inspection was the most common, and it was the sole or deciding factor in $50.6 \%$ of cases in which the window selection strategy was reported, and a third of all papers), method of selecting electrodes for the main statistical analysis (11 options, the two most commonly reported strategies were analysing all recorded channels without grouping, $24.3 \%$, and visual inspection, $23.1 \%$ of cases in which the strategy 
Fig. 3 Variability and frequencies of different choices when making methodological decisions. The $y$ axis shows methodological information that was examined, while the $x$ axis shows the percentage of each option. All percentages are relative to No - the number of cases relevant for the variable in question (e.g., studies in which it was possible or appropriate to apply a procedure, or in which the relevant information was available). More details can be found in Supplement 6d. Note: * average reference is grouped into one option in this row; ** unique combinations of electrode layouts and their groupings into factors

\section{Consistency in methodological decisions}

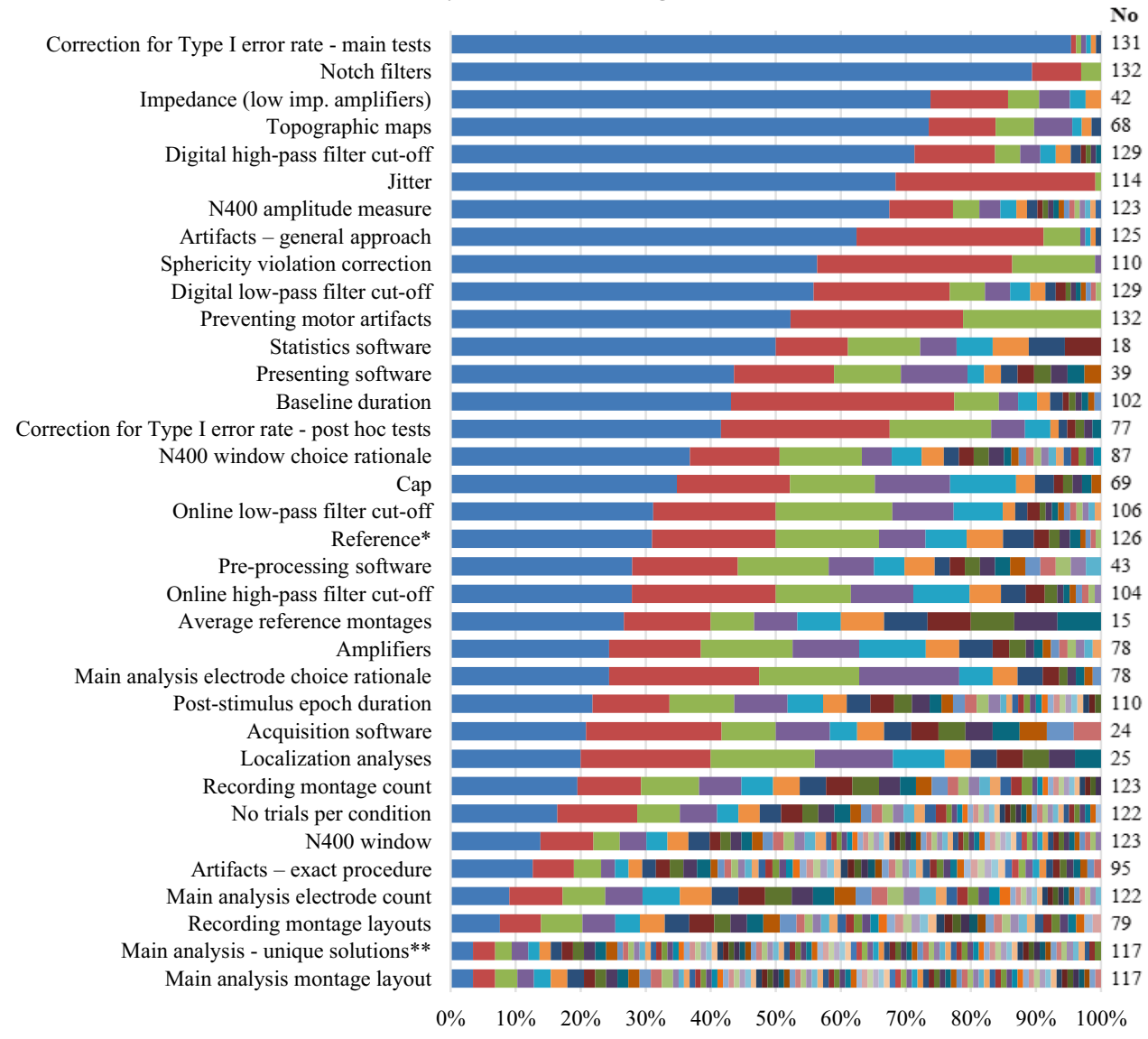

could be identified), and post hoc comparisons (no correction in $42.9 \%$ of all papers in which post hoc tests were described, and 9 different corrections, out of which Bonferroni and Tukey HSD were the most frequent). A borderline case in this category of variables was epoch duration, which included 32 different epochs, but the $1000 \mathrm{~ms}$ one was used in $21.8 \%$ of all cases.

Finally, there were methodological decisions to which almost every team of authors took a different approach. When it comes to specific methods of artifact detection and elimination, 67 unique pipelines were found, each of them used in only one paper or a handful of publications. Regardless, as long as artifacts are properly eliminated from the trials used for averaging, all these artifact detection strategies, despite their variability, should produce comparable outcomes. Another decision on which publications diverged was the recording electrode montage: 50 different layouts of between $1-144$ electrodes ( 34 different montage sizes) were identified in papers in which this information was provided. The most frequently used montage was found in six papers. The average montage had 46.33 electrodes $(\mathrm{SD}=36.08)$, while the most common montage size was 64 electrodes (19.5\% of papers in which this information was available). In some cases, electrode montages are fixed, but in the future, part of the variability in recording site montages could be reduced by considering consistency with previous literature when selecting electrode locations for recording when this is relevant (e.g., average reference, full scalp analyses). When it comes to the average reference, it was not possible to determine how many different electrode montages were used to produce it, because the montages were not described in half of these papers. Still, it can be seen based on the reported montage sizes, that there were at least 14 different montages in 27 papers in which the electrode montage was reported, with as little as 19 or as many as 144 electrodes. Therefore, the topographic distributions of effects obtained from these montages, especially those with fewer than 64 electrodes, differ to an unknown extent (see Junghöfer et al., 1999; Keil et al., 2014; Luck, 2005, 2014; Picton et al., 2000). The number of trials per condition also varied widely between studies. As few as 6 and as many as 400 trials were presented per condition in the reviewed studies ( $\mathrm{M}=60.78, \mathrm{SD}=51.57,49$ different options), and about half of all studies (56.6\%) had between 20-50 trials per condition. As a result of predominantly data-dependent strategies for the analysis window selection, the N400 amplitude was measured from 69 different latency ranges, $76.8 \%$ of which were used in a single study. Similarly, the 
Fig. 4 N400 window choices in all datasets, i.e., experiments on separate participant groups, in papers in which an N400 analysis window was reported $(\mathrm{N}=133$ datasets from 120 papers from which both sample size and latency window could be extracted). If a paper reported multiple analysis windows or multiple experiments on the same subjects, it was represented by a single window, whose lower and upper bounds were the most extreme measures of all windows reported in this paper. Bands show N400 latency ranges for all individual datasets. The heat bar in the bottom displays frequency of including each time point (1 ms) in the N400 latency range, weighted by the number of participants per condition for each dataset. Shades of green show differences between the lowest (white) and the maximum weighted frequency (dark green). This graph has been created by modifying the template made available by Neyeloff et al. (2012)

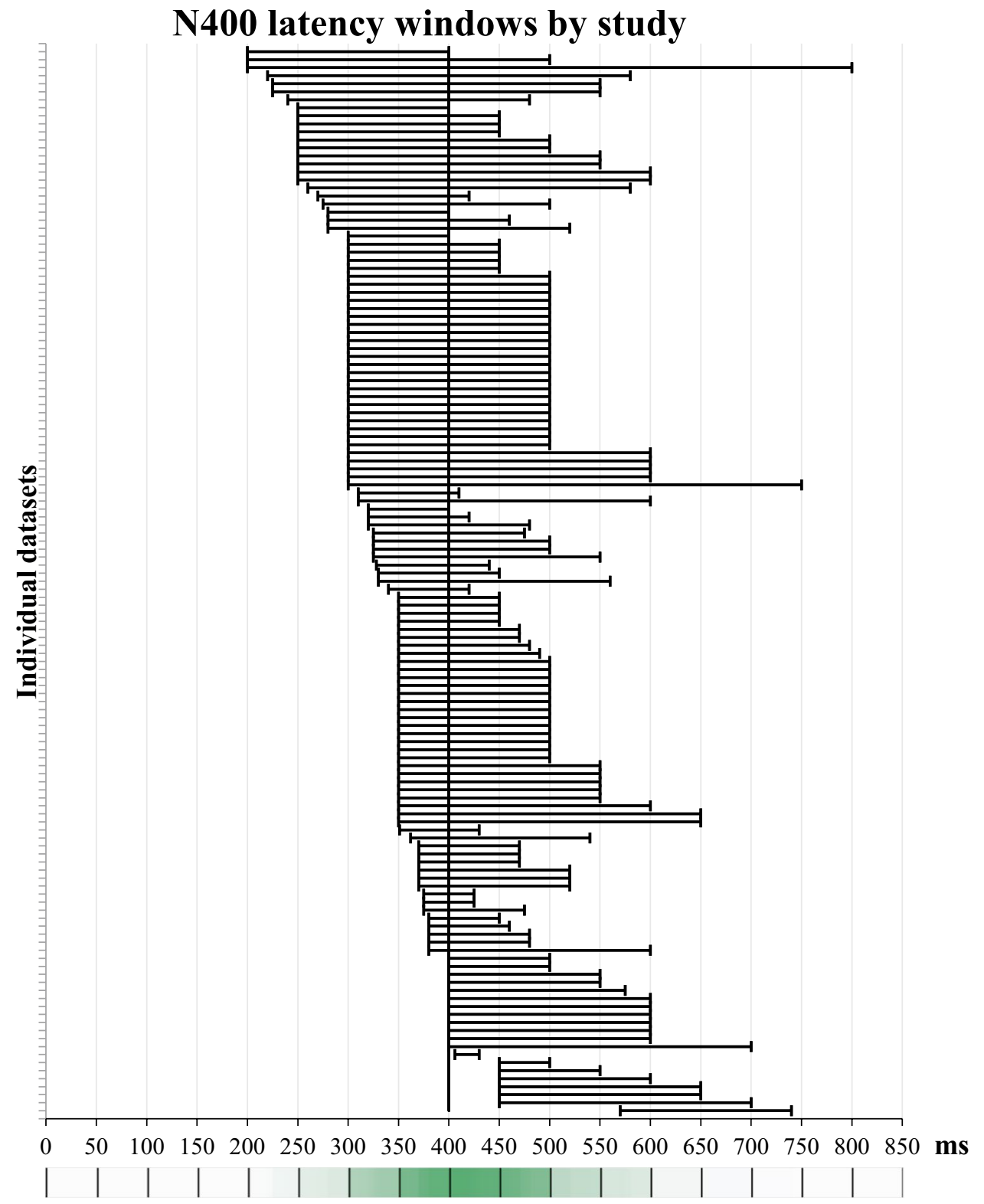

All datasets, weighted by number of participants per condition
N400 effect was determined based on 66 different electrodes combined into 93 unique sets, of 41 different sizes varying between $1-144$. Furthermore, these sets were subjected to 99 different main statistical analyses.

What could a future researcher rely on to make an a priori decision about statistical comparisons, given this variability in the N400 measurement window and measurement electrodes choice? To answer this question, we extracted latencies and electrode locations from individual experiments to extract the overlapping time points and electrode locations.

Regarding measurement window choices, latency ranges for a total of 133 experiments were extracted from 120 papers which had information on both sample size and N400 latency range. Next, each millisecond in the $0-850 \mathrm{~ms}$ poststimulus epoch received a score based on the number of times it fell within the N400 range and the number of participants per group in the experiments in which it was found. The results showed that there was a sudden drop in scores after $500 \mathrm{~ms}$, and that there were two large increases - after 300 and $350 \mathrm{~ms}$. The increase following $300-\mathrm{ms}$ point was slightly larger compared to $350 \mathrm{~ms}$, and $300-500 \mathrm{~ms}$ was also the most frequently used measurement window. Therefore, if future researchers wanted to select their N400 measurement window a priori based on the existing literature, the 300-500 ms window would be the option most supported by previous literature, at least in the case of experiments with pictures as target stimuli. Figure 4 shows all latency ranges 


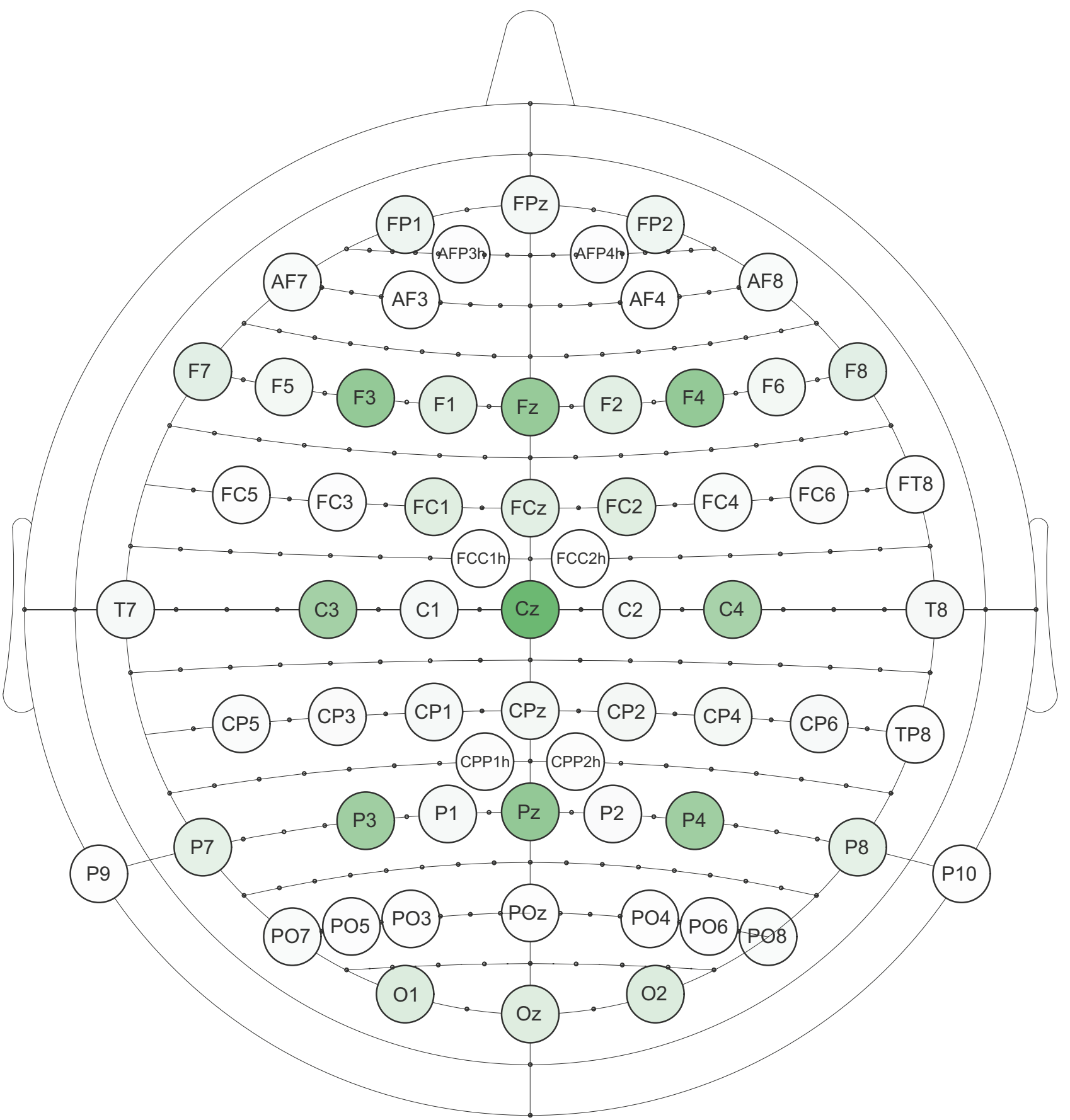

Fig. 5 The montage shows all electrodes that were used for measurement of the N400 in the main statistical analysis, regardless of the reference point. Only studies with 12 or fewer electrodes were used to generate this montage, because larger montages more frequently included analyses of the entire scalp with broadly distributed elec-

that were used for the N400 measurement and analysis in the reviewed literature, and its heat bar is a visual representation of the weighted frequencies for all time points. Supplement $7 \mathrm{~d}$ contains a more detailed description of this trodes. If a paper included more than one experiment with different subjects, both experiments were included in the analysis separately. Shades of green show differences between the lowest (white) and the maximum frequency (dark green) of using an electrode, weighted by the number of participants per condition for each experiment

analysis, while Supplement 6c contains an Excel version of Fig. 4 with all scores for the heat bar.

In order to investigate the variability in analysis montage choices, we examined which electrodes were reported in studies in which up to 12 electrode sites were 
analysed. As explained in the Codebook (Supplement 3), this cut-off point was chosen because montages with more than 12 electrode sites typically involved analysing all or most of the recorded sites, which were distributed over the entire scalp, while the smaller recording and analysis montages were more frequently targeted on the N400 effect location.

For this purpose, data on 65 experiments conducted on different samples was extracted from 58 publications. Within analysis montages used in these experiments, 66 different channels were found. Frequency of using each channel for analysing data from the selected 65 experiments was registered, and, additionally, this information was weighted by the number of participants per group. All electrodes used in the analyses are shown in Fig. 5, in which weighted frequency of each site is presented using colour scale. More information on this analysis can be found in Supplement 6d, while the Excel calculations can be found in Supplement 6a. Nine electrodes stood out compared to others: F3, Fz, F4, C3, Cz, $\mathrm{C} 4, \mathrm{P} 3, \mathrm{Pz}$, and P4. Each of these electrodes was used in 23 or more experiments, compared to all other sites, which were included in analyses of 10 or fewer experiments. The results were the same when data was weighted by the number of participants per group. Notably, no electrode appeared in more than about a half of all studies: $\mathrm{Cz}$ was the electrode most commonly used for the N400 measurement, compared to the other eight sites, and it was included in $55.4 \%$ cases.

The described variability can be partly attributed to differences in the recording montage, but not entirely, given that montages frequently overlapped on many electrode sites. The variability was more likely the consequence of the method of electrode location selection, which was frequently data-driven and often allowed for researcher degrees of freedom (for more information on channel selection strategies, see Supplement 7d).

One shortcoming of the previous analysis is the variability in references used to measure the N400 effect, as its topographic distribution varies depending on the reference. As it was shown earlier, most of the references were mastoid, a smaller proportion average, and other references were infrequent, so Fig. 5 is most heavily influenced by these two references. Therefore, the montage shown in Fig. 5 shows the variability of the electrode location choices in this field, but it would not be the best grounds for making a priori decisions in future studies. To provide guidance for deciding on the analysis montage based on previous literature, we repeated the same analysis of electrode locations, but only for 24 experiments reported in 18 publications which reported using a mastoid or earlobe reference, which are expected to yield the same distribution. Only cases in which it could be verified that the reference was not physically linked were included, because physical linking would also influence topographic distribution. In total, 47 different electrodes were found, and the most frequent choices were F3, Fz, F4, C3, Cz, and C4. They were used in 12-14 experiments and stood out the most when frequencies were weighted by the number of participants per group. Like in the case of the analysis of all experiments, $\mathrm{P} 3, \mathrm{Pz}$ and $\mathrm{P} 4$ were also frequent, but they did not stand out this time. Each was used in 8 experiments, while other electrodes were used in 1-6 experiments, and the weighted frequencies were closer to the rest of electrodes than to F3, Fz, F4, C3, Cz, or $\mathrm{C} 4$. To summarize, future researchers who use mastoid, earlobe or similar references, and want to select electrodes for the N400 measurement a priori based on the previous literature, should pick F3, Fz, F4, C3, Cz, and C4. Like in the case of the previous analysis, Excel sheets with all frequencies and calculations can be found in Supplement 6a.

Due to the variability in montages used to create the average reference and the number of papers using other references, it was not possible to provide specific guidelines for montages other than mastoid/earlobe.

\section{How Often Do Researchers Deviate From Guidelines for Good Practice? Which Deviations are the Most Common?}

While "it depends" how many participants and trials are needed for a sufficiently powered study, as Boudewyn et al. (2018) put it, it is safe to say that studies with fewer than ten participants per condition and studies in which no more than thirty trials per condition were averaged together were underpowered to detect smaller within-group and betweengroup effects. There were $11.4 \%$ studies in the first group, and $28.6 \%$ of studies in the second group.

Among the recording and pre-processing steps, a few issues were found. Inappropriately high high-pass filters ( $\geq 0.3 \mathrm{~Hz}$ half-amplitude or half-power, see Luck, 2014; Tanner et al., 2015), either analog or digital, were found in $10.6 \%$ of cases, while inappropriately low low-pass filters ( $<20 \mathrm{~Hz}$ half-amplitude, see Luck, 2014) were found in $7.6 \%$ of publications (for a discussion about half-amplitude vs. half-power cut-off, see Supplement 7c). Linked mastoid or earlobe references were used in about a quarter of all studies $(23.0 \%$, assuming that the description of recording with a linked reference was correct;(for issues with using linked references, see Keil et al., 2014; Miller et al., 1991; Picton et al., 2000). When average reference was used, the montages were not always sufficiently large and distributed over a large area of the head, as it is recommended (Junghöfer et al., 1999; Keil et al., 2014; Picton et al., 2000). While all baseline durations were appropriately long $(100+\mathrm{ms})$, some studies may benefit from extending the baseline from 100 to $200 \mathrm{~ms}$. This could enhance amplitude measurement stability, especially if the N400 latency range extends beyond 500 ms (Luck, 2014). Other baseline-related issues 
included showing waveforms before baseline correction in graphs and noise or confounding activity in the baseline period. It is difficult to assess prevalence of deviating from the best practices in artifact detection and correction due to limited information available and diversity of methods which were described, but suboptimal strategies were found in some cases (e.g., rejecting trials exclusively based on a fixed base-to-peak threshold, for a discussion about artifact elimination methods, see Luck, 2014). Finally, not all reported orders of pre-processing steps were optimal, or in some cases even acceptable (e.g., if high-pass filtering was applied after averaging).

The aspect of the reviewed studies which warrants the most attention is data analysis, more specifically, Type I error rate probability. There were several decision points which contributed to the high probability of finding a false positive result in the reviewed studies. As mentioned earlier, strategies for selecting the time window and electrodes for the N400 measurement were frequently data-dependent, despite the relatively stable latency and spatial distribution of the N400 (see Kutas \& Federmeier, 2011). Data-dependent strategies are not an issue per se, as long as appropriate corrections for multiple comparisons are being made (e.g., mass univariate approach; see Groppe et al., 2011). However, the papers included in this review frequently opted for strategies such as visually inspecting waveforms to select time windows and electrodes, combined with subjecting the same waveforms to statistical analyses appropriate only for a priori comparisons. Such strategies are sometimes called "double-dipping" because they involve relying on the same dataset to select a subset of data to be analysed and also conduct the analysis (Kriegeskorte et al., 2009). As Luck and Gaspelin (2017) explain, such approaches include implicit and practically uncorrected comparisons that are being made prior to analysing data, and it is not appropriate to apply statistical analyses such as ANOVA on subsets of data selected this way as if the selection had been made a priori, because the Type I error rate is compromised. The second major point that contributed to the Type I error rate inflation was the number of analyses which was conducted. For example, out of 115 papers which used ANOVA, ANCOVA or MANOVA for the N400 analysis, 70.4\% papers had more than one (M)AN(C)OVA model without correction for multiple comparisons, and more than a half (53.9\%) had more than four such models $(\mathrm{M}=7.12$ models, $\mathrm{SD}=10.35)$. The total number of uncorrected models went up to 576 (one for each experimental factor, electrode site and short window) in one study. Additionally, the N400 was not the only component that was analysed in $88.4 \%$ of publications - between 1-14 additional components were analysed in these studies $(\mathrm{M}=2.63, \mathrm{SD}=2.58)$. When the number of components is multiplied by the number of analyses employed to investigate them, as well as with the number of factors in each analysis, the number of comparisons becomes so large that it is not appropriate to treat main effects as a priori comparisons. Taking all this together, it is urgent that ERP field makes a shift towards more appropriate data analysis strategies in the future.

Finally, some practices are not deviations from guidelines for good practice but adopting alternatives more broadly may benefit future studies. Three such practices were registered: jittering inter-stimulus interval, delaying motor response with a cue to respond to avoid overlap with ERP components if combined with jittering, and boosting statistical power by lowering impedances even when high-input impedance amplifiers are used (for more information about impedances, see Kappenman \& Luck, 2010).

\section{Trends Over Time}

As shown in Table 1, the oldest paper included in this review was published in 1988. Reflecting growth in ERP use, the papers are not distributed evenly over the years. Instead, their number grew over time. Approximately a half of all papers $(50.8 \%)$ were published in the last ten years, since 2010.

In this section, we will present a brief comparison between the 25 papers published between 1988-2000, when the first detailed guidelines for ERP research were published (Picton et al., 2000), and the 25 publications which came out since 2015, a year after presenting the latest version of the guidelines (Keil et al., 2014), to show how improvements in ERP methodology and recommendations were reflected in practice.

Study Design and Sampling Several aspects of study design have changed over time. First, the more recent studies had more participants per condition $\left(\mathrm{M}_{\mathrm{old}}=15.36, \mathrm{n}_{\text {new }}=18.52\right)$, even though between-group designs, which are less powerful, were more frequent in the older literature $\left(\mathrm{f}_{\text {old }}=24 \%\right.$, $\mathrm{f}_{\text {new }}=8 \%$ ). The contemporary studies also had more trials per condition, even after excluding two studies, one in each group, which had unusually large numbers of trials per condition $\left(\mathrm{M}_{\text {old }}=39.38, \mathrm{M}_{\text {new }}=50.74\right.$, excluding outliers). The two groups of studies did not differ a lot, however, when it comes to reporting on how many trials were averaged together - about half of papers in both groups did not report outcomes of artifact rejection, although the number was slightly higher in the sample of older papers $\left(\mathrm{f}_{\text {old }}=56 \%\right.$, $\mathrm{f}_{\text {new }}=44 \%$ for not reporting). Jittering interstimulus or intertrial interval became more widespread over time $\left(\mathrm{f}_{\text {old }}=12 \%\right.$, $\mathrm{f}_{\text {new }}=40 \%$ ), while self-paced timing was more frequent in the older literature $\left(f_{\text {old }}=16 \%, f_{\text {new }}=0 \%\right)$. Authors of the earlier studies used both tasks with delayed response and no response to the N400-eliciting stimulus as a method to eliminate brain activity related to motor response equally 
$\left(f_{\text {no response }}=20 \%, f_{\text {delayed response }}=20 \%, f_{\text {neither }}=60 \%\right)$, while delayed motor response was a preferred solution in the more recent studies $\left(\mathrm{f}_{\text {no response }}=8 \%, \mathrm{f}_{\text {delayed response }}=32 \%\right.$, $\mathrm{f}_{\text {neither }}=60 \%$ ).

Apparatus and Software Equipment and software were more frequently described in the more recent publications (cap reports: $\mathrm{f}_{\text {old }}=28 \%, \mathrm{f}_{\text {new }}=76 \%$; amplifiers reports: $\mathrm{f}_{\text {old }}=44 \%, \mathrm{f}_{\text {new }}=76 \%$; software reports: $\mathrm{f}_{\text {old }}=0-20 \%$, $\mathrm{f}_{\text {new }}=36-68 \%$, depending on the category). In addition to more recent guidelines recommending more detailed reports, the increase in software reporting can likely be attributed to more recent development of widely available commercial and open-access software packages, as well as more complex procedures for data processing and analysis, offered by these packages.

Recording and Pre-Processing The older publications reported impedances more frequently than more recent ones $\left(\mathrm{f}_{\text {old }}=80 \%, \mathrm{f}_{\text {new }}=64 \%\right.$ ). This is related to the fact that highimpedance amplifiers were often used in the contemporary studies $\left(f_{\text {new }}=40 \%\right)$, but none of the authors of the more dated papers reported using such equipment. As explained in the section on impedances, papers on studies in which high-impedance amplifiers were used, did not contain alternative data quality indicators when impedance information was not available.

Recording montages have become bigger since the early studies. The average number of electrodes in the montage increased form $\mathrm{M}_{\text {old }}=13.38$ to $\mathrm{M}_{\text {new }}=55.04$. Montage sizes in the older papers were also more diverse, while 4 out of 10 the more recent studies were recorded with 62-64 active channels.

Voltage reference of choice has also changed over time. Linked mastoid or earlobe references were often used in the early studies $\left(f_{\text {old }}=56 \%\right)$, while other solutions were diverse and infrequent. In the latest studies, linked references have been abandoned for superior offline references, mean mastoids $\left(\mathrm{f}_{\text {new }}=40 \%\right)$ and average reference $\left(\mathrm{f}_{\text {new }}=28 \%\right)$. In case of the latter, the authors described the recording montage in only one paper.

Expansion of digital filtering tools allowed filtering data with a narrower bandpass offline. Among the older publications, five had reports on low-pass digital filters and one mentioned high-pass filtering. In contrast, data was filtered digitally in more than half of the more recent studies $\left(\mathrm{f}_{\text {high-pass }}=56 \%, \mathrm{f}_{\text {low-pass }}=64 \%\right.$ ). Online filters were described in all of the older publications. The more recent papers, however, usually only had descriptions of analog filters when digital filters were not used. Only 3 out of 16 contemporary papers which mention digital filters also included information on analog filters. Roll-off was described by $8 \%$ older and $24 \%$ of the more recent papers, and it was provided for offline filters in all cases but one. Cut-off type was specified for all filters in $60 \%$ of the older publications, and in $12 \%$ of the more recent ones. Even though almost all sources (Cook \& Miller, 1992; Keil et al., 2014; Luck, 2005, 2014; Picton et al., 2000) advise against notch filters, they have not been abandoned yet $\left(\mathrm{f}_{\text {old }}=12 \%, \mathrm{f}_{\text {new }}=16 \%\right)$.

Similarly, development of better artifact correction algorithms and increased availability of programs which implement them resulted in a shift from primarily rejection $\left(\mathrm{f}_{\text {old }}=88 \%\right)$ to combining rejection with correction ( $\mathrm{f}_{\text {old }}=32 \%$ for rejection, $\mathrm{f}_{\text {new }}=48 \%$ for combined methods).

Baseline duration differed between the old and the new papers, too. Data was most frequently baseline-corrected relative to $200 \mathrm{~ms}$ baseline in the new studies $\left(\mathrm{f}_{100}=24 \%\right.$, $\mathrm{f}_{200}=52 \%$ ), and relative to $100 \mathrm{~ms}$ in the oldest studies $\left(\mathrm{f}_{100}=44 \%, \mathrm{f}_{200}=20 \%\right)$.

Unfortunately, descriptions of the order of operations have not become more precise (in $\mathrm{f}_{\text {new }}=\mathrm{f}_{\text {old }}=64 \%$ of papers, the order of operations could be at least assumed).

Measurement and Analysis While reporting on the measurement analysis window has changed, the main strategy to choose it has not. The contemporary papers included rationale for choosing analysis window more frequently ( $f_{\text {old }}=48 \%, f_{\text {new }}=64 \%$ for reports that did have it) and used multiple different arguments to justify the choice more often $\left(\mathrm{f}_{\text {old }}=0 \%, \mathrm{f}_{\text {new }}=20 \%\right)$. The main strategy in both groups was visual inspection $\left(f_{\text {old }}=f_{\text {new }}=32 \%\right)$. Although this is understandable in the case of early papers, when there were not many options for data analysis or previous studies to provide grounds for specific hypotheses, the most recent guidelines advocate against this practice (Keil et al., 2014). Mean amplitude was the main amplitude measure in both studies $\left(f_{\text {old }}=68 \%, f_{\text {new }}=64 \%\right)$, while the use of peak amplitude has decreased $\left(\mathrm{f}_{\text {old }}=28 \%, \mathrm{f}_{\text {new }}=12 \%\right)$.

Conversely, frequency of reporting on selection of electrodes for the main statistical analysis has not changed (old: $\mathrm{f}_{\text {not reported }}=48 \%, \mathrm{f}_{\text {inconclusive }}=4 \%$; new: $\mathrm{f}_{\text {not reported }}=40 \%$, $\mathrm{f}_{\text {inconclusive }}=4 \%$ ), but the most frequently used analysis strategy has. The most common approach in early studies was to avoid selecting electrodes for analysis by treating all recorded channels as levels of one factor $\left(f_{\text {old }}=28 \%\right.$, $\mathrm{f}_{\text {new }}=12 \%$ ), while the contemporary studies rely on visual inspection more often $\left(\mathrm{f}_{\text {old }}=4 \%, \mathrm{f}_{\text {new }}=28 \%\right.$ ). Like recording montages, analysis montages have also increased $\left(M_{\text {old }}=11.37, M_{\text {new }}=21.76\right)$. Consequently, the risk of Type I error has increased with time. This risk was reduced on a different front: more recent papers had fewer $(\mathrm{M}) \mathrm{AN}(\mathrm{C})$ OVA models $\left(\mathrm{M}_{\mathrm{old}}=10.14, \mathrm{M}_{\text {new }}=4.22^{4}\right.$; papers with only

\footnotetext{
4 This difference remains after removing three outliers with more than 40 ANOVAs.
} 
one model: $\mathrm{f}_{\text {old }}=8 \%, \mathrm{f}_{\text {new }}=32 \%$ ), as well as fewer ERP components taken from the same waveforms $\left(\mathrm{M}_{\text {old }}=2.76\right.$, $\mathrm{M}_{\text {new }}=2.12$; papers with only one component: $\mathrm{f}_{\text {old }}=44 \%$, $\mathrm{f}_{\text {new }}=80 \%$ ).

Regarding visualization of spatial distribution, maps have become more widespread $\left(f_{\text {old }}=2 \%, f_{\text {new }}=44 \%\right)$. Topographic distribution analyses have also changed. In the group of older papers, PCA analysis was used in two studies (8\%), and it has not been used in the more recent ones. On the other hand, there were four more recent publications (16\%) in which LORETA-based analyses were employed.

Overall Reproducibility Overall, the two groups of studies had similar frequencies of omitting methodological details or presenting them in an ambiguous way. The average contemporary study had some inconclusive information on 1.6 out of $70^{5}$ variables, and some information was omitted in 14.92 out of 70 cases on average. Similarly, the older publications had 1.52 variable values with inconclusive and 16 values with missing information.

Providing supplementary methodology materials has become more frequent, although not a norm, in line with the Open Access movement and wider options for storing research data online. Sharing at least brief descriptions of stimuli has become more frequent $\left(\mathrm{f}_{\text {old }}=8 \%, \mathrm{f}_{\text {new }}=16 \%\right)$. On top of this, two of the most recent studies (8\%) have also published some of their ERP data, albeit only mean component amplitudes in one case.

\section{The Detailed Picture}

Given the number of variables and papers covered in this study, a thorough report on all results surpasses the format of a journal article. In the Big Picture section of this paper, we have attempted to provide an overview of the main findings, but readers interested in a more detailed account of available guidelines and our results regarding any aspect of ERP methodology included in this study, can find them in supplementary materials linked below:

1. Study design and sampling (Supplement 7a): experiments and factors; trial structure and timing; sample size; number of trials (presented and included in analyses).

2. Equipment and software (Supplement 7b).

3. Recording and pre-processing (Supplement 7c): impedance; recording montage (active sites); reference and re-referencing; filtering (high-pass and low-pass filters cut-off and roll-off, other filters); baseline; post-

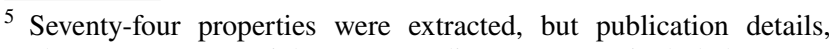
such as paper type (article vs. proceedings) were not included.
}

stimulus epoch (length and overlap with overt response or the next stimulus); eliminating artifacts; order of operations.

4. N400 amplitude measurement and statistical analysis (Supplement 7d): amplitude measurement (grounds for choosing analysis window, latency range, amplitude measure); main statistical analysis of the N400 amplitude (grounds for choosing electrode locations; which sites were chosen for the main analysis; analysis); additional analyses of the N400 component; correction for Type I error rate and other corrections; topographic distribution analyses and visualization; general considerations regarding measurement and analysis.

\section{Conclusion}

What should be the main takeaway from this study? While this review has highlighted some of the shortcomings of the existing N400 literature, our goal was not to show that all studies have issues. It is likely that there are no perfect studies, as ERP data recording, processing and analysis are incredibly complex processes, and our analysis of trends over time has shown that many aspects of ERP methodology and reporting have improved over time. Moreover, these very standards we have today, which were cited in this study, result from continuous endeavours by the ERP research community to improve methods and analyses of ERP data. Many concerns which were discussed here are not unique to ERP research - on the contrary, they are shared with similar fields of study, such as fMRI, psychophysiological recordings, and, in some respects, even behavioural research. This study, therefore, serves to highlight some common issues, to provide guidance for a priori time window and electrode selection, and to advocate for more rigorous methodology and more comprehensive reporting in future.

This systematic review, although extensive, is far from exhaustive. Picture-evoked N400 is not the only ERP measure, and many methodology decisions were not considered in this review - from statistical power, to study design and hypotheses, participant exclusion criteria, compliance of graphs with recommendations for appropriate visualization of ERP data, details of more complex statistical analyses, and others. These questions remain to be explored in future studies.

In addition to expanding the scope of the literature review, two additional questions naturally come to mind. The first question is- how much does the observed variability in pre-processing and analysis pipelines affect our knowledge about the N400? One way to answer this question is to implement Multiverse Analysis approach (Steegen et al., 2016) to examine to what extent the variability present in the N400 literature affects results of experiments (e.g., Author(s); Kappenman \& Luck, 2010; Tanner et al., 2015). 
Regardless of the outcomes of such analyses, basing a priori decisions about the N400 window, locations or measurement reference on the existing literature, as suggested in this paper, would improve coherency and comparability between future reports.

The second question is-what we can do to improve reporting on the N400, and more broadly ERP, studies. For one, we hope that future researchers, especially the ones who are just diving into the field of ERP research, will find our account of the most frequently omitted items and examples of wordings that are insufficiently informative helpful. Secondly, given the amount of detail that is required for a thorough report on ERP data recording and pre-processing, it is challenging to fit everything in a typical journal article format, which is why researchers were often in position to choose which aspects they can describe in more details, and which they need to shorten as much as possible. While it is also important to strive to provide as accurate and as detailed report in a journal paper, the more recent availability of online repositories for supplementary materials helps overcome this challenge by providing additional space for all information that cannot fit within a given limit of characters available for the paper itself. Finally, several initiatives which call for action and propose a solution in the form of checklists and reporting templates have arisen in the past few years (Gau et al., 2021; Keil et al., 2014; Pernet et al., 2018). To advance this effort within ERP specifically, the item-level details arising from this systematic review have been adapted into a reporting template designed to make reporting easier and more accurate: Agreed Reporting Template for EEG Methodology - International Standard (ARTEM-IS) for ERP research (Styles et al., 2021). Given the number of details that needs to be provided for an ERP study to be fully reproducible, these initiatives provide promising tools for reducing omissions and ambiguous reports on methodological details.

Supplementary Information The online version contains supplementary material available at https://doi.org/10.1007/s11065-021-09513-4.

Acknowledgements All authors contributed to the study conception and design. Material preparation, data collection and analysis were performed by A $\check{S}, \mathrm{VJ}$ and VK. The first draft of the manuscript was written by AŠ. VK, ESK, and SJS commented on all versions of the manuscript. All authors read and approved the final manuscript. This study was supported by Singapore's National Research Foundation under the Science of Learning grant NRF2016-SOL002-011 (SJS), grant OI179033 by Ministry of Education, Science and Technological Development of the Republic of Serbia (AŠ and VK), and a Nanyang Assistant Professor Start Up Grant M4081215.SS0 (SJS). The authors wish to thank Marija Brković and Nemanja Antonijević for their help with producing Fig. 5, Dr Andrej Savić, for discussions about EEG recording and signal pre-processing, and Dr Remi Gau for his suggestions on how to improve Figs. 2 and 3. Part of this data was presented at the 21st ESCOP conference, held in Arona, Tenerife, in September 2019.
Open Access This article is licensed under a Creative Commons Attribution 4.0 International License, which permits use, sharing, adaptation, distribution and reproduction in any medium or format, as long as you give appropriate credit to the original author(s) and the source, provide a link to the Creative Commons licence, and indicate if changes were made. The images or other third party material in this article are included in the article's Creative Commons licence, unless indicated otherwise in a credit line to the material. If material is not included in the article's Creative Commons licence and your intended use is not permitted by statutory regulation or exceeds the permitted use, you will need to obtain permission directly from the copyright holder. To view a copy of this licence, visit http://creativecommons.org/licen ses/by/4.0/.

\section{References}

Baetens, K., Van der Cruyssen, L., Vandekerckhove, M., \& Van Overwalle, F. (2014). ERP correlates of script chronology violations. Brain and Cognition, 91, 113-122. https://doi.org/10.1016/j. bandc.2014.09.005

Balconi, M., \& Pozzoli, U. (2005). Comprehending semantic and grammatical violations in Italian. N400 and P600 comparison with visual and auditory stimuli. Journal of Psycholinguistic Research, 34(1), 71-98.

Balconi, M., \& Vitaloni, S. (2014). N400 Effect When a Semantic Anomaly is Detected in Action Representation. A Source Localization Analysis. Journal of Clinical Neurophysiology, 31(1), 58-64. https://doi.org/10.1097/WNP.0000000000000017

Barrett, S. E., \& Rugg, M. D. (1989). Event-related potentials and the semantic matching of faces. Neuropsychologia, 27(7), 913-922. https://doi.org/10.1016/0028-3932(89)90067-5

Barrett, S. E., \& Rugg, M. D. (1990). Event-related potentials and the semantic matching of pictures. Brain and Cognition, 14(2), 201-212. https://doi.org/10.1016/0278-2626(90)90029-N

Barrett, S. E., Rugg, M. D., \& Perrett, D. I. (1988). Event-related potentials and the matching of familiar and unfamiliar faces. Neuropsychologia, 26(1), 105-117. https://doi.org/10.1016/0028-3932(88) 90034-6

Bensafi, M., Pierson, A., Rouby, C., Farget, V., Bertrand, B., Vigouroux, M., Jouvent, R., \& Holley, A. (2002). Modulation of visual event-related potentials by emotional olfactory stimuli. Neurophysiologie Clinique/clinical Neurophysiology, 32(6), 335-342. https://doi.org/10.1016/S0987-7053(02)00337-4

Blackford, T., Holcomb, P. J., Grainger, J., \& Kuperberg, G. R. (2012). A funny thing happened on the way to articulation: N400 attenuation despite behavioral interference in picture naming. Cognition, 123(1), 84-99. https://doi.org/10.1016/j.cognition.2011. 12.007

Bobes, M. A., Valdes-Sosa, M., \& Olivares, E. I. (1994). An ERP Study of Expectancy Violation in Face Perception. Brain and Cognition, 26(1), 1-22. https://doi.org/10.1006/brcg.1994.1039

Boldini, A., Algarabel, S., Ibanez, A., \& Bajo, M. T. (2008). Perceptual and semantic familiarity in recognition memory: An eventrelated potential study. NeuroReport, 19(3), 305-308. https://doi. org/10.1097/WNR.0b013e3282f4cf73

Boudewyn, M. A., Luck, S. J., Farrens, J. L., \& Kappenman, E. S. (2018). How many trials does it take to get a significant ERP effect? It Depends. Psychophysiology, 55(6), e13049. https://doi. org/10.1111/psyp.13049

Bouten, S., Pantecouteau, H., \& Debruille, J. B. (2018). Looking for effects of qualia on event-related brain potentials of close others in search for a cause of the similarity of qualia assumed across 
individuals. F1000Research, 3, 316. https://doi.org/10.12688/ f1000research.5977.3

Boutonnet, B., McClain, R., \& Thierry, G. (2014). Compound words prompt arbitrary semantic associations in conceptual memory. Frontiers in Psychology, 5, 222. https://doi.org/10.3389/fpsyg.2014.00222

Bramão, I., Francisco, A., Inácio, F., Faísca, L., Reis, A., \& Petersson, K. M. (2012). Electrophysiological evidence for colour effects on the naming of colour diagnostic and noncolour diagnostic objects. Visual Cognition, 20(10), 1164-1185. https://doi.org/ 10.1080/13506285.2012.739215

Butler, D. L., Mattingley, J. B., Cunnington, R., \& Suddendorf, T. (2013). Different Neural Processes Accompany Self-Recognition in Photographs Across the Lifespan: An ERP Study Using Dizygotic Twins. PLoS One, 8(9).

Cansino, S., Hernández-Ramos, E., \& Trejo-Morales, P. (2012). Neural correlates of source memory retrieval in young, middle-aged and elderly adults. Biological Psychology, 90(1), 33-49. https://doi. org/10.1016/j.biopsycho.2012.02.004

Carp, J. (2012). The secret lives of experiments: Methods reporting in the fMRI literature. NeuroImage, 63(1), 289-300. https://doi.org/ 10.1016/J.NEUROIMAGE.2012.07.004

Castle, P. C., Van Toller, S., \& Milligan, G. (2000). The effect of odour priming on cortical EEG and visual ERP responses. International Journal of Psychophysiology, 36(2), 123-131. https://doi.org/10. 1016/S0167-8760(99)00106-3

Chambers, C. (2017). The Seven Deadly Sins of Psychology: A Manifesto for Reforming the Culture of Scientific Practice. Princeton University Press. https://doi.org/10.2307/j.ctvc779w5

Cohn, N., Paczynski, M., Jackendoff, R., Holcomb, P. J., \& Kuperberg, G. R. (2012). (Pea)nuts and bolts of visual narrative: Structure and meaning in sequential image comprehension. Cognitive Psychology, 65(1), 1-38. https://doi.org/10.1016/j.cogpsych.2012.01.003

Cook, E. W., \& Miller, G. A. (1992). Digital Filtering: Background and Tutorial for Psychophysiologists. Psychophysiology. https://doi. org/10.1111/j.1469-8986.1992.tb01709.x

Cooper, T. J., Harvey, M., Lavidor, M., \& Schweinberger, S. R. (2007). Hemispheric asymmetries in image-specific and abstractive priming of famous faces: Evidence from reaction times and event-related brain potentials. Neuropsychologia, 45(13), 29102921. https://doi.org/10.1016/j.neuropsychologia.2007.06.005

Davis, H., Davis, P. A., Loomis, A. L., Hervey, E. N., \& Hobart, G. (1939). Electrical reactions of the human brain to auditory stimulation during sleep. Journal of Neurophysiology, 2, 500-514.

Davis, P. A. (1939). Effects of acoustic stimuli on the waking human brain. Journal of Neurophysiology, 2, 494-499.

Debruille, J. B., Pineda, J., \& Renault, B. (1996). N400-like potentials elicited by faces and knowledge inhibition. Brain Research. Cognitive Brain Research, 4(2), 133-144. https://doi.org/10.1016/ 0926-6410(96)00032-8

DeLong, K. A., Urbach, T. P., \& Kutas, M. (2005). Probabilistic word pre-activation during language comprehension inferred from electrical brain activity. Nature Neuroscience, 8(8), 1117-1121. https://doi.org/10.1038/nn1504

DeLong, K. A., Urbach, T. P., \& Kutas, M. (2017). Concerns with Nieuwland et al. (2017). University of California. http://kutaslab. ucsd.edu/pdfs/FinalDUK17Comment9LabStudy.pdf

Delorme, A., Sejnowski, T., \& Makeig, S. (2007). Enhanced detection of artifacts in EEG data using higher-order statistics and independent component analysis. NeuroImage, 34(4), 1443-1449. https://doi.org/10.1016/j.neuroimage.2006.11.004

Demiral, ŞB., Malcolm, G. L., \& Henderson, J. M. (2012). ERP correlates of spatially incongruent object identification during scene viewing: Contextual expectancy versus simultaneous processing. Neuropsychologia, 50(7), 1271-1285. https://doi.org/10.1016/j. neuropsychologia.2012.02.011
Diéguez-Risco, T., Aguado, L., Albert, J., \& Hinojosa, J. A. (2013). Faces in context: Modulation of expression processing by situational information. Social Neuroscience, 8(6), 601-620. https:// doi.org/10.1080/17470919.2013.834842

Dominguez-Martinez, E., Parise, E., Strandvall, T., \& Reid, V. M. (2015). The Fixation Distance to the Stimulus Influences ERP Quality: An EEG and Eye Tracking N400 Study. PLoS One, 10(7).

Donchin, E., Callaway, E., Cooper, R., Desmedt, J. E., Goff, W. R., Hillyard, S. A., \& Sutton, S. (1977). Publication criteria for studies of evoked potentials (EP) in man: Methodology and publication criteria. In J. E. Desmedt (Ed.), Progress in clinical neurophysiology: Vol. 1. Attention, voluntary contraction and event-related cerebral potentials (pp. 1-11). Karger.

Duncan, C. C., Barry, R. J., Connolly, J. F., Fischer, C., Michie, P. T., Näätänen, R., Polich, J., Reinvang, I., \& Van Petten, C. (2009). Event-related potentials in clinical research: Guidelines for eliciting, recording, and quantifying mismatch negativity, P300, and N400. Clinical Neurophysiology, 120(11), 1883-1908. https:// doi.org/10.1016/j.clinph.2009.07.045

Dyck, M., \& Brodeur, M. B. (2015). ERP evidence for the influence of scene context on the recognition of ambiguous and unambiguous objects. Neuropsychologia, 72, 43-51. https://doi.org/10.1016/j. neuropsychologia.2015.04.023

Eddy, M. D., \& Holcomb, P. J. (2009). Electrophysiological evidence for size invariance in masked picture repetition priming. Brain and Cognition, 71(3), 397-409. https://doi.org/10.1016/j.bandc.2009.05.006

Eddy, M. D., \& Holcomb, P. J. (2010). The temporal dynamics of masked repetition picture priming effects: Manipulations of stimulus-onset asynchrony (SOA) and prime duration. Brain Research, 1340, 24-39. https://doi.org/10.1016/j.brainres.2010. 04.024

Eddy, M. D., \& Holcomb, P. J. (2011). Invariance to rotation in depth measured by masked repetition priming is dependent on prime duration. Brain Research, 1424, 38-52. https://doi.org/10.1016/j. brainres.2011.09.036

Eddy, M. D., Schmid, A., \& Holcomb, P. J. (2006). Masked repetition priming and event-related brain potentials: A new approach for tracking the time-course of object perception. Psychophysiology, 43(6), 564-568. https://doi.org/10.1111/j.1469-8986.2006.00455.x

Eimer, M. (2000). Event-related brain potentials distinguish processing stages involved in face perception and recognition. Clinical Neurophysiology, 111(4), 694-705. https://doi.org/10.1016/ S1388-2457(99)00285-0

Federmeier, K. D., \& Kutas, M. (2002). Picture the difference: Electrophysiological investigations of picture processing in the two cerebral hemispheres. Neuropsychologia, 40(7), 730-747. https:// doi.org/10.1016/S0028-3932(01)00193-2

Friedman, D. (1990). Cognitive Event-Related Potential Components During Continuous Recognition Memory for Pictures. Psychophysiology, 27(2), 136-148. https://doi.org/10.1111/j.1469-8986. 1990.tb00365.x

Ganis, G., \& Kutas, M. (2003). An electrophysiological study of scene effects on object identification. Cognitive Brain Research, 16(2), 123-144. https://doi.org/10.1016/S0926-6410(02)00244-6

Ganis, G., Kutas, M., \& Sereno, M. I. (1996). The Search for "Common Sense": An Electrophysiological Study of the Comprehension of Words and Pictures in Reading. Journal of Cognitive Neuroscience, 8(2), 89-106. https://doi.org/10.1162/jocn. 1996.8.2.89

Gao, C., Hermiller, M. S., Voss, J. L., Guo, C. (2015). Basic perceptual changes that alter meaning and neural correlates of recognition memory Frontiers in Human. Neuroscience 9 https://doi.org/ 10.3389/fnhum.2015.00049

Gau, R., Gould van Praag, C., van Mourik, T., Wiebels, K., Adolfi, F. G., Scarpazza, C., Ruotsalainen, I., Tepper, A., Sjoerds, Z., 
Simon, J., Klapwijk, E., Hortensius, R., Bartlett, J. E., \& Moreau, D. (2021). COBIDAS checklist. https://doi.org/10.17605/OSF. IO/ANVQY

Gelman, A., \& Loken, E. (2013). The garden of forking paths: Why multiple comparisons can be a problem, even when there is no "fishing expedition" or "p-hacking" and the research hypothesis was posited ahead of time. http://www.stat.columbia.edu/ gelman/research/unpublished/p_hacking.pdf

Gierych, E., Milner, R., \& Michalski, A. (2005). ERP Responses to Smile-Provoking Pictures. Journal of Psychophysiology, 19(2), 77-90. https://doi.org/10.1027/0269-8803.19.2.77

Giglio, A. C. A., Minati, L., \& Boggio, P. S. (2013). Throwing the banana away and keeping the peel: Neuroelectric responses to unexpected but physically feasible action endings. Brain Research, 1532, 56-62. https://doi.org/10.1016/j.brainres.2013. 08.017

Greenhouse, S. W., \& Geisser, S. (1959). On methods in the analysis of profile data. Psychometrika, 24(2), 95-112. https://doi.org/ 10.1007/BF02289823

Grigor, J. (1999). The Effect of Odour Priming on Long Latency Visual Evoked Potentials of Matching and Mismatching Objects. Chemical Senses, 24(2), 137-144. https://doi.org/10.1093/ chemse/24.2.137

Groppe, D. M., Urbach, T. P., \& Kutas, M. (2011). Mass univariate analysis of event-related brain potentials/fields I: A critical tutorial review. Psychophysiology, 48(12), 1711-1725. https://doi. org/10.1111/j.1469-8986.2011.01273.x

Gui, P., Ku, Y., Li, L., Li, X., Bodner, M., Lenz, F. A., Wang, L., \& Zhou, Y.-D. (2017). Neural correlates of visuo-tactile crossmodal paired-associate learning and memory in humans. Neuroscience, 362, 181-195. https://doi.org/10.1016/j.neuroscience.2017.08.035

Gunter, T. C., \& Bach, P. (2004). Communicating hands: ERPs elicited by meaningful symbolic hand postures. Neuroscience Letters, 372(1-2), 52-56. https://doi.org/10.1016/j.neulet.2004.09.011

Hamm, J. P., Johnson, B. W., \& Kirk, I. J. (2002). Comparison of the N300 and N400 ERPs to picture stimuli in congruent and incongruent contexts. Clinical Neurophysiology, 113(8), 1339-1350. https://doi.org/10.1016/S1388-2457(02)00161-X

Handy, T. C. (2005). Event-related potentials: A methods handbook. MIT Press.

Harris, J. D., Cutmore, T. R. H., O'Gorman, J., Finnigan, S., \& Shum, D. (2009). Neurophysiological indices of perceptual object priming in the absence of explicit recognition memory. International Journal of Psychophysiology, 71(2), 132-141. https://doi.org/10. 1016/j.ijpsycho.2008.08.005

Herring, D. R., Taylor, J. H., White, K. R., \& Crites, S. L. (2011). Electrophysiological responses to evaluative priming: The LPP is sensitive to incongruity. Emotion, 11(4), 794-806. https://doi. org/10.1037/a0022804

Hirschfeld, G., Feldker, K., \& Zwitserlood, P. (2012). Listening to "flying ducks": Individual differences in sentence-picture verification investigated with ERPs. Psychophysiology, 49(3), 312-321. https://doi.org/10.1111/j.1469-8986.2011.01315.x

Hirschfeld, G., Jansma, B., Bölte, J., \& Zwitserlood, P. (2008). Interference and facilitation in overt speech production investigated with event-related potentials. NeuroReport, 19(12), 1227-1230. https://doi.org/10.1097/WNR.0b013e328309ecd1

Holcomb, P. J., \& McPherson, W. B. (1994). Event-related brain potentials reflect semantic priming in an object decision task. Brain and Cognition, 24(2), 259-276. https://doi.org/10.1006/brcg. 1994.1014

Hoogeveen, H. R., Jolij, J., Ter Horst, G. J., \& Lorist, M. M. (2016). Brain Potentials Highlight Stronger Implicit Food Memory for Taste than Health and Context Associations. PLoS One, 11(5).

Huffmeijer, R., Tops, M., Alink, L. R. A., Bakermans-Kranenburg, M. J., \& van Ijzendoorn, M. H. (2011). Love withdrawal is related to heightened processing of faces with emotional expressions and incongruent emotional feedback: Evidence from ERPs. Biological Psychology, 86(3), 307-313. https://doi.org/10.1016/j.biopsycho. 2011.01.003

Ioannidis, J. P. A., Munafò, M. R., Fusar-Poli, P., Nosek, B. A., \& David, S. P. (2014). Publication and other reporting biases in cognitive sciences: Detection, prevalence, and prevention. Trends in Cognitive Sciences, 18(5), 235-241. https://doi.org/10.1016/j. tics.2014.02.010

Jemel, B., Calabria, M., Delvenne, J. F., Crommelinck, M., \& Bruyer, R. (2003). Differential involvement of episodic and face representations in ERP repetition effects. NeuroReport, 14(3), 525-530. https://doi.org/10.1097/01.wnr.0000057864.05120.ba

Jordan, T. R., \& Thomas, S. M. (1999). Memory for normal and distorted pictures: Modulation of the ERP repetition effect. Journal of Psychophysiology, 13(4), 224-233. https://doi.org/ 10.1027//0269-8803.13.4.224

Junghöfer, M., Elbert, T., Tucker, D., \& Braun, C. (1999). The polar average reference effect: A bias in estimating the head surface integral in EEG recording. Clinical Neurophysiology, 110(6), 1149-1155. https://doi.org/10.1016/S1388-2457(99)00044-9

Kaczer, L., Timmer, K., Bavassi, L., \& Schiller, N. O. (2015). Distinct morphological processing of recently learned compound words: An ERP study. Brain Research, 1629, 309-317. https:// doi.org/10.1016/j.brainres.2015.10.029

Kappenman, E. S., \& Luck, S. J. (2010). The effects of electrode impedance on data quality and statistical significance in ERP recordings. Psychophysiology, 47(5), 888-904. https://doi.org/ 10.1111/j.1469-8986.2010.01009.x

Kappenman, E. S., \& Luck, S. J. (2016). Best Practices for EventRelated Potential Research in Clinical Populations. Biological Psychiatry: Cognitive Neuroscience and Neuroimaging, 1(2), 110-115. https://doi.org/10.1016/j.bpsc.2015.11.007

Keil, A., Debener, S., Gratton, G., Junghöfer, M., Kappenman, E. S., Luck, S. J., Luu, P., Miller, G. A., \& Yee, C. M. (2014). Committee report: Publication guidelines and recommendations for studies using electroencephalography and magnetoencephalography. Psychophysiology, 51(1), 1-21. https://doi.org/10.1111/ psyp. 12147

Khateb, A., Pegna, A. J., Landis, T., Mouthon, M. S., \& Annoni, J.-M. (2010). On the Origin of the N400 Effects: An ERP Waveform and Source Localization Analysis in Three Matching Tasks. Brain Topography, 23(3), 311-320. https://doi.org/ 10.1007/s10548-010-0149-7

Khushaba, R. N., Greenacre, L., Al-Timemy, A., \& Al-Jumaily, A. (2015). Event-related Potentials of Consumer Preferences. Procedia Computer Science, 76, 68-73. https://doi.org/10.1016/j. procs.2015.12.277

Kiefer, M. (2001). Perceptual and semantic sources of category-specific effects: Event-related potentials during picture and word categorization. Memory \& Cognition, 29(1), 100-116. https:// doi.org/10.3758/BF03195745

Kiefer, M., Liegel, N., Zovko, M., \& Wentura, D. (2017). Mechanisms of masked evaluative priming: Task sets modulate behavioral and electrophysiological priming for picture and words differentially. Social Cognitive and Affective Neuroscience, 12(4), 596-608. https://doi.org/10.1093/scan/ nsw 167

Kiefer, M., Sim, E.-J., Helbig, H., \& Graf, M. (2011). Tracking the Time Course of Action Priming on Object Recognition: Evidence for Fast and Slow Influences of Action on Perception. Journal of Cognitive Neuroscience, 23(8), 1864-1874. https:// doi.org/10.1162/jocn.2010.21543

Koester, D., \& Schiller, N. O. (2008). Morphological priming in overt language production: Electrophysiological evidence 
from Dutch. NeuroImage, 42(4), 1622-1630. https://doi.org/ 10.1016/j.neuroimage.2008.06.043

Kovalenko, L. Y., Chaumon, M., \& Busch, N. A. (2012). A Pool of Pairs of Related Objects (POPORO) for Investigating Visual Semantic Integration: Behavioral and Electrophysiological Validation. Brain Topography, 25(3), 272-284. https://doi. org/10.1007/s10548-011-0216-8

Kovic, V., Plunkett, K., \& Westermann, G. (2009). Shared and/or separate representations of animate/inanimate categories: An ERP study. Psihologija, 42(1), 5-26. https://doi.org/10.2298/ PSI0901005K

Kriegeskorte, N., Simmons, W. K., Bellgowan, P. S. F., \& Baker, C. I. (2009). Circular analysis in systems neuroscience: The dangers of double dipping. Nature Neuroscience, 12(5), 535-540. https://doi.org/10.1038/nn.2303

Kuipers, J. R., \& Thierry, G. (2011). N400 Amplitude Reduction Correlates with an Increase in Pupil Size. Frontiers in Human Neuroscience, 5, 61. https://doi.org/10.3389/fnhum.2011.00061

Küper, K., Liesefeld, A. M., \& Zimmer, H. D. (2015). ERP evidence for hemispheric asymmetries in abstract but not exemplar-specific repetition priming. Psychophysiology, 52(12), 1610-1619. https:// doi.org/10.1111/psyp. 12542

Kutas, M., \& Federmeier, K. D. (2011). Thirty years and counting: Finding meaning in the $\mathrm{N} 400$ component of the event related brain potential (ERP). Annual Review of Psychology, 62, 621-647. https://doi.org/10.1146/annurev.psych.093008.131123

Kutas, M., \& Hillyard, S. A. (1980). Reading senseless sentences: brain potentials reflect semantic incongruity. In Science (New York, N.Y.) 207(4427), 203-205. https://doi.org/10.1126/science.7350657

Kutas, M., \& Iragui, V. (1998). The N400 in a semantic categorization task across 6 decades. Electroencephalography and Clinical Neurophysiology, 108(5), 456-471.

Lensink, S. E., Verdonschot, R. G., \& Schiller, N. O. (2014). Morphological priming during language switching: An ERP study. Frontiers in Human Neuroscience, 8, 995. https://doi.org/10. 3389/fnhum.2014.00995

Li, T.-T., \& Lu, Y. (2014). The subliminal affective priming effects of faces displaying various levels of arousal: An ERP study. Neuroscience Letters, 583, 148-153. https://doi.org/10.1016/j.neulet. 2014.09.027

Liao, S., Su, Y., Wu, X., \& Qiu, J. (2011). The Poggendorff illusion effect influenced by top-down control: Evidence from an eventrelated brain potential study. NeuroReport, 22(15), 739-743. https://doi.org/10.1097/WNR.0b013e32834ab40b

Lin, M., Wang, C., Cheng, S., \& Cheng, S. (2011). An event-related potential study of semantic style-match judgments of artistic furniture. International Journal of Psychophysiology, 82(2), 188-195. https://doi.org/10.1016/j.ijpsycho.2011.08.007

Liu, C., Tardif, T., Mai, X., Gehring, W. J., Simms, N., \& Luo, Y.-J. (2010). What's in a name? Brain activity reveals categorization processes differ across languages. Human Brain Mapping, 31(11), 1786-1801. https://doi.org/10.1002/hbm.20974

Lu, A., Xu, G., Jin, H., Mo, L., Zhang, J., \& Zhang, J. X. (2010). Electrophysiological evidence for effects of color knowledge in object recognition. Neuroscience Letters, 469(3), 405-410. https://doi. org/10.1016/j.neulet.2009.12.039

Luck, S. J. (2005). An Introducation to the Event-Related Potential Technique. MIT Press.

Luck, S. J. (2014). An Introduction to the Event-Related Potential Technique (2nd ed.). MIT Press.

Luck, S. J., \& Gaspelin, N. (2017). How to Get Statistically Significant Effects in Any ERP Experiment (and Why You Shouldn't). Psychophysiology, 54(1), 146-157. https://doi.org/10.1111/psyp.12639

Lüdtke, J., Friedrich, C. K., De Filippis, M., \& Kaup, B. (2008). Eventrelated Potential Correlates of Negation in a Sentence-Picture
Verification Paradigm. Journal of Cognitive Neuroscience, 20(8), 1355-1370. https://doi.org/10.1162/jocn.2008.20093

Maffongelli, L., Bartoli, E., Sammler, D., Kölsch, S., Campus, C., Olivier, E., Fadiga, L., \& D’Ausilio, A. (2015). Distinct brain signatures of content and structure violation during action observation. Neuropsychologia, 75, 30-39. https://doi.org/10.1016/j.neuropsychologia.2015.05.020

Maillard, L., Barbeau, E. J., Baumann, C., Koessler, L., Bénar, C., Chauvel, P., \& Liégeois-Chauvel, C. (2011). From Perception to Recognition Memory: Time Course and Lateralization of Neural Substrates of Word and Abstract Picture Processing. Journal of Cognitive Neuroscience, 23(4), 782-800. https://doi.org/10.1162/ jocn.2010.21434

Mandikal Vasuki, P. R., Sharma, M., Ibrahim, R. K., \& Arciuli, J. (2017). Musicians' Online Performance during Auditory and Visual Statistical Learning Tasks. Frontiers in Human Neuroscience, 11, 114. https://doi.org/10.3389/fnhum.2017.00114

Manfredi, M., Adorni, R., \& Proverbio, A. M. (2014). Why do we laugh at misfortunes? An electrophysiological exploration of comic situation processing. Neuropsychologia, 61, 324-334. https://doi.org/10.1016/j.neuropsychologia.2014.06.029

Mao, W., \& Wang, Y. (2007). Various conflicts from ventral and dorsal streams are sequentially processed in a common system. Experimental Brain Research, 177(1), 113-121. https://doi. org/10.1007/s00221-006-0651-z

McPherson, W. B., \& Holcomb, P. J. (1999). An electrophysiological investigation of semantic priming with pictures of real objects. Psychophysiology, 36(1), 53-65. https://doi.org/10.1017/S0048 577299971196

Mecklinger, A. (1998). On the modularity of recognition memory for object form and spatial location: A topographic ERP analysis. Neuropsychologia, 36(5), 441-460. https://doi.org/10.1016/ S0028-3932(97)00128-0

Miller, G. A., Lutzenberger, W., \& Elbert, T. (1991). The linkedreference issue in EEG and ERP recording. Journal of Psychophysiology, 5(3), 273-276. https://psycnet.apa.org/record/ 1992-11892-001

Mnatsakanian, E. V., \& Tarkka, I. M. (2003). Matching of familiar faces and abstract patterns: Behavioral and high-resolution ERP study. International Journal of Psychophysiology, 47(3), 217227. https://doi.org/10.1016/S0167-8760(02)00154-X

Mnatsakanian, E. V., \& Tarkka, I. M. (2004). Familiar-face recognition and comparison: Source analysis of scalp-recorded event-related potentials. Clinical Neurophysiology, 115(4), 880-886. https:// doi.org/10.1016/j.clinph.2003.11.027

Moher, D., Liberati, A., Tetzlaff, J., Altman, D. G., \& Group, T. P. (2009). Preferred Reporting Items for Systematic Reviews and Meta-Analyses: The PRISMA Statement. PLoS Medicine, 6(7), e1000097. https://doi.org/10.1371/journal.pmed.1000097

Mudrik, L., Lamy, D., \& Deouell, L. Y. (2010). ERP evidence for context congruity effects during simultaneous object-scene processing. Neuropsychologia, 48(2), 507-517. https://doi.org/10. 1016/j.neuropsychologia.2009.10.011

Mudrik, L., Shalgi, S., Lamy, D., \& Deouell, L. Y. (2014). Synchronous contextual irregularities affect early scene processing: Replication and extension. Neuropsychologia, 56, 447-458. https://doi. org/10.1016/j.neuropsychologia.2014.02.020

Münte, T. F., Brack, M., Grootheer, O., Wieringa, B. M., Matzke, M., \& Johannes, S. (1998). Brain potentials reveal the timing of face identity and expression judgments. Neuroscience Research, 30(1), 25-34. https://doi.org/10.1016/S0168-0102(97)00118-1

Neumann, M. F., \& Schweinberger, S. R. (2008). N250r and N400 ERP correlates of immediate famous face repetition are independent of perceptual load. Brain Research, 1239, 181-190. https://doi. org/10.1016/j.brainres.2008.08.039

Neyeloff, J. L., Fuchs, S. C., \& Moreira, L. B. (2012). Meta-analyses and Forest plots using a microsoft excel spreadsheet: Step-by-step 
guide focusing on descriptive data analysis. BMC Research Notes, 5(1), 52. https://doi.org/10.1186/1756-0500-5-52

Nielsen-Bohlman, L., \& Knight, R. T. (1995). Prefrontal alterations during memory processing in aging. Cerebral Cortex, 5(6), 541-549. https://doi.org/10.1093/cercor/5.6.541

Nieuwland, M. S., Politzer-Ahles, S., Heyselaar, E., Segaert, K., Darley, E., Kazanina, N., Von Grebmer, Zu., Wolfsthurn, S., Bartolozzi, F., Kogan, V., Ito, A., Mézière, D., Barr, D. J., Rousselet, G. A., Ferguson, H. J., Busch-Moreno, S., Fu, X., Tuomainen, J., Kulakova, E., ... Huettig, F. (2018). Large-scale replication study reveals a limit on probabilistic prediction in language comprehension. eLife, 7, e33468. https://doi.org/10.7554/eLife.33468

Nigam, A., Hoffman, J. E., \& Simons, R. F. (1992). N400 to semantically anomalous pictures and words. Journal of Cognitive Neuroscience, 4(1), 15-22. https://doi.org/10.1162/jocn.1992.4.1.15

Niu, Y., Xue, C., Wang, H., Zhou, L., Zhang, J., Peng, N., \& Jin, T. (2016). Event-Related Potential Study on Visual Selective Attention to Icon Navigation Bar of Digital Interface. In D. Harris (Ed.), Engineering Psychology and Cognitive Ergonomics (EPCE 2016) (Vol. 9736, pp. 79-89). Springer International Publishing AG. https://doi.org/10.1007/978-3-319-40030-3_9

Nosek, B. A., Alter, G., Banks, G. C., Borsboom, D., Bowman, S. D., Breckler, S. J., Buck, S., Chambers, C. D., Chin, G., Christensen, G., Contestabile, M., Dafoe, A., Eich, E., Freese, J., Glennerster, R., Goroff, D., Green, D. P., Hesse, B., Humphreys, M., ... Yarkoni, T. (2015). SCIENTIFIC STANDARDS. Promoting an open research culture. Science (New York, N.Y.), 348(6242), 1422-1425. https://doi.org/10.1126/science.aab2374

Olivares, E. I., \& Iglesias, J. (2010). Brain potential correlates of the "internal features advantage" in face recognition. Biological Psychology, 83(2), 133-142. https://doi.org/10.1016/j.biopsycho.2009.11.011

Olivares, E. I., Iglesias, J., \& Bobes, M. A. (1999). Searching for face-specific long latency ERPs: A topographic study of effects associated with mismatching features. Cognitive Brain Research, 7(3), 343-356. https://doi.org/10.1016/S0926-6410(98)00038-X

Olivares, E. I., Iglesias, J., \& Rodríguez-Holguín, S. (2003). LongLatency ERPs and Recognition of Facial Identity. Journal of Cognitive Neuroscience, 15(1), 136-151. https://doi.org/10.1162/ 089892903321107873

Olivares, E. I., Saavedra, C., Trujillo-Barreto, N. J., \& Iglesias, J. (2013). Long-term information and distributed neural activation are relevant for the "internal features advantage" in face processing: Electrophysiological and source reconstruction evidence. Cortex, 49(10), 2735-2747. https://doi.org/10.1016/j.cortex. 2013.08.001

Ortega, R., Lopez, V., \& Aboitiz, F. (2008). Voluntary modulations of attention in a semantic auditory-visual matching Task: An ERP study. Biological Research, 41(4), 453-460. https://doi.org/10. 4067/S0716-97602008000400010

Ortiz, M. J., Grima Murcia, M. D., \& Fernandez, E. (2017). Brain processing of visual metaphors: An electrophysiological study. Brain and Cognition, 113, 117-124. https://doi.org/10.1016/j. bandc.2017.01.005

Ousterhout, T. (2015). N400 congruency effects from emblematic gesture probes following sentence primes. In Szakal, A (Ed.), INES 2015 - IEEE 19TH INTERNATIONAL CONFERENCE ON INTELLIGENT ENGINEERING SYSTEMS (pp. 411-415). IEEE. https://doi.org/10.1109/ines.2015.7329744

Paz-Caballero, D., Cuetos, F., \& Dobarro, A. (2006). Electrophysiological evidence for a natural/artifactual dissociation. Brain Research, 1067(1), 189-200. https://doi.org/10.1016/j.brainres. 2005.10.046

Perez-Abalo, M. C., Rodriguez, R., Bobes, M. A., Gutierrez, J., \& Valdes-Sosa, M. (1994). Brain potentials and the availability of semantic and phonological codes over time. Neuroreport, 5(16), 2173-2177. http://www.ncbi.nlm.nih.gov/pubmed/7865770
Pergola, G., Foroni, F., Mengotti, P., Argiris, G., \& Rumiati, R. I. (2017). A neural signature of food semantics is associated with body-mass index. Biological Psychology, 129, 282-292. https:// doi.org/10.1016/j.biopsycho.2017.09.001

Pernet, C., Garrida, M., Gramfort, A., Maurits, N., Michel, C., Pang, E., Salmelin, R., Schoffelen, J.-M., Valdes-Sosa, P., \& Puce, A. (2018). Best Practices in Data Analysis and Sharing in Neuroimaging using MEEG. https://doi.org/10.31219/osf.io/a8dhx

Picton, T. W., Bentin, S., Berg, P., Donchin, E., Hillyard, S. A., Johnson, R., Jr., Miller, G. A., Ritterr, W., Ruchkin, D. S., Rugg, M. D., \& Taylor, M. J. (2000). Guidelines for using human event-related potentials to study cognition: Recording standards and publication criteria. Psychophysiology, 37(2), 127-152. https://doi.org/ 10.1111/1469-8986.3720127

Pietrowsky, R., Kuhmann, W., Krug, R., Molle, M., Fehm, H. L., \& Born, J. (1996). Event-Related Brain Potentials during Identification of Tachistoscopically Presented Pictures. Brain and Cognition, 32(3), 416-428. https://doi.org/10.1006/brcg.1996.0074

Pratarelli, M. E. (1994). Semantic Processing of Pictures and Spoken Words: Evidence from Event-Related Brain Potentials. Brain and Cognition, 24(1), 137-157. https://doi.org/10.1006/brcg.1994.1008

Proverbio, A. M., Azzari, R., \& Adorni, R. (2013). Is there a left hemispheric asymmetry for tool affordance processing? Neuropsychologia, 51(13), 2690-2701. https://doi.org/10.1016/j.neuropsychologia. 2013.09.023

Proverbio, A. M., Calbi, M., Manfredi, M., \& Zani, A. (2014). Comprehending Body Language and Mimics: An ERP and Neuroimaging Study on Italian Actors and Viewers. PLoS One, 9(3).

Proverbio, A. M., Del Zotto, M., \& Zani, A. (2007). The emergence of semantic categorization in early visual processing: ERP indices of animal vs. artifact recognition. BMC Neuroscience, 8(1), 24. https://doi.org/10.1186/1471-2202-8-24

Proverbio, A. M., Gabaro, V., Orlandi, A., \& Zani, A. (2015). Semantic brain areas are involved in gesture comprehension: An electrical neuroimaging study. Brain and Language, 147, 30-40. https:// doi.org/10.1016/j.bandl.2015.05.002

Proverbio, A. M., \& Riva, F. (2009). RP and N400 ERP components reflect semantic violations in visual processing of human actions. Neuroscience Letters, 459(3), 142-146. https://doi.org/10.1016/j. neulet.2009.05.012

Proverbio, A. M., Riva, F., \& Zani, A. (2010). When neurons do not mirror the agent's intentions: Sex differences in neural coding of goal-directed actions. Neuropsychologia, 48(5), 1454-1463. https://doi.org/10.1016/j.neuropsychologia.2010.01.015

Riby, L. M., \& Orme, E. (2013). A familiar pattern? Semantic memory contributes to the enhancement of visuo-spatial memories. Brain and Cognition, 81(2), 215-222. https://doi.org/10.1016/j.bandc. 2012.10.011

Rojas, J.-C., Contero, M., Camba, J. D., Concepcion Castellanos, M., Garcia-Gonzalez, E., \& Gil-Macian, S. (2016). Design Perception: Combining Semantic Priming with Eye Tracking and EventRelated Potential (ERP) Techniques to Identify Salient Product Visual Attributes. Proc. ASME 2015 International Mechanical Engineering Congress and Exposition, Volume 11: Systems, Design, and Complexity.

Saavedra, C., Iglesias, J., \& Olivares, E. I. (2010). Event-Related Potentials Elicited by the Explicit and Implicit Processing of Familiarity in Faces. Clinical EEG and Neuroscience, 41(1), 24-31. https://doi.org/10.1177/155005941004100107

Savic, O., Savic, A. M., \& Kovic, V. (2017). Comparing the temporal dynamics of thematic and taxonomic processing using eventrelated potentials. PLoS One, 12(12).

Schendan, H. E., \& Ganis, G. (2012). Electrophysiological Potentials Reveal Cortical Mechanisms for Mental Imagery, Mental Simulation, and Grounded (Embodied) Cognition. Frontiers in Psychology, 3, 329. https://doi.org/10.3389/fpsyg.2012.00329 
Schendan, H. E., Ganis, G. (2015). Top-down modulation of visual processing and knowledge after $250 \mathrm{~ms}$ supports object constancy of category decisions. Frontiers in Psychology 6 https:// doi.org/10.3389/fpsyg.2015.01289

Schendan, H. E., \& Kutas, M. (2003). Time Course of Processes and Representations Supporting Visual Object Identification and Memory. Journal of Cognitive Neuroscience, 15(1), 111-135. https://doi.org/10.1162/089892903321107864

Schleepen, T. M. J., Markus, C. R., \& Jonkman, L. M. (2014). Dissociating the effects of semantic grouping and rehearsal strategies on event-related brain potentials. International Journal of Psychophysiology, 94(3), 319-328. https://doi.org/10.1016/j. ijpsycho.2014.09.007

Schweinberger, S. R., Pfütze, E.-M., \& Sommer, W. (1995). Repetition priming and associative priming of face recognition: Evidence from event-related potentials. Journal of Experimental Psychology: Learning, Memory, and Cognition, 21(3), 722-736. https:// doi.org/10.1037/0278-7393.21.3.722

Shibata, H., Gyoba, J., \& Suzuki, Y. (2009). Event-related potentials during the evaluation of the appropriateness of cooperative actions. Neuroscience Letters, 452(2), 189-193. https://doi.org/ 10.1016/j.neulet.2009.01.042

Simos, P. G., \& Molfese, D. L. (1997). Event-Related Potentials in a Two-Choice Task Involving Within-Form Comparisons of Pictures and Words. International Journal of Neuroscience, 90(3-4), 233-253. https://doi.org/10.3109/00207459709000641

Šoškić, A., Jovanović, V., Styles, S. J., Kappenman, E. S., \& Kovic, V. (2021, January 22). How to do better N400 studies: reproducibility, consistency and adherence to research standards in the existing literature. https://doi.org/10.17605/OSF.IO/N426J

Steegen, S., Tuerlinckx, F., Gelman, A., \& Vanpaemel, W. (2016). Increasing Transparency Through a Multiverse Analysis. Perspectives on Psychological Science. https://doi.org/10.1177/ 1745691616658637

Steffensen, S. C., Ohran, A. J., Shipp, D. N., Hales, K., Stobbs, S. H., \& Fleming, D. E. (2008). Gender-selective effects of the P300 and N400 components of the visual evoked potential. Vision Research, 48(7), 917-925. https://doi.org/10.1016/j.visres.2008.01.005

Stuss, D., Picton, T., Cerri, A., Leech, E., \& Stethem, L. (1992). Perceptual closure and object identification: Electrophysiological responses to incomplete pictures. Brain and Cognition, 19(2), 253-266. https://doi.org/10.1016/0278-2626(92)90047-P

Styles, S. J., Kovic, V., Ke, H., \& Šoškić, A. (2021). Towards ARTEMIS: an evidence-based Agreed Reporting Template for Electrophysiology Methods - International Standard. PsyArXiv. https:// doi.org/10.31234/osf.io/myn7t

Supp, G. G., Schlögl, A., Fiebach, C. J., Gunter, T. C., Vigliocco, G., Pfurtscheller, G., \& Petsche, H. (2005). Semantic memory retrieval: Cortical couplings in object recognition in the N400 window. European Journal of Neuroscience, 21(4), 1139-1143. https://doi.org/10.1111/j.1460-9568.2005.03906.x

Tanner, D., Morgan-Short, K., \& Luck, S. J. (2015). How inappropriate high-pass filters can produce artifactual effects and incorrect conclusions in ERP studies of language and cognition. Psychophysiology, 52, 997-1009. https://doi.org/10.1111/psyp.12437

Taylor, M. J., \& Baldeweg, T. (2002). Application of EEG, ERP and intracranial recordings to the investigation of cognitive functions in children. Developmental Science, 5(3), 318-334. https://doi. org/10.1111/1467-7687.00372

Trenner, M. U., Schweinberger, S. R., Jentzsch, I., \& Sommer, W. (2004). Face repetition effects in direct and indirect tasks: An event-related brain potentials study. Cognitive Brain Research, 21(3), 388-400. https://doi.org/10.1016/j.cogbrainres.2004.06.017

Võ, M.L.-H., \& Wolfe, J. M. (2013). Differential Electrophysiological Signatures of Semantic and Syntactic Scene Processing.
Psychological Science, 24(9), 1816-1823. https://doi.org/10. 1177/0956797613476955

Wang, R. W. Y., Kuo, H.-C., \& Chuang, S.-W. (2017). Humor drawings evoked temporal and spectral EEG processes. Social Cognitive and Affective Neuroscience, 12(8), 1359-1376. https://doi.org/10. 1093/scan/nsx054

Wang, Y., Zhang, Q. (2016). Affective Priming by Simple Geometric Shapes: Evidence from Event-related Brain Potentials. Frontiers in Psychology 7 https://doi.org/10.3389/fpsyg.2016.00917

Wang, Y., Cui, L., Wang, H., Tian, S., \& Zhang, X. (2004). The sequential processing of visual feature conjunction mismatches in the human brain. Psychophysiology, 41(1), 21-29. https://doi.org/10. 1111/j.1469-8986.2003.00134.x

Wang, Y., Tian, S., Wang, H., Cui, L., Zhang, Y., \& Zhang, X. (2003). Event-related potentials evoked by multi-feature conflict under different attentive conditions. Experimental Brain Research, 148(4), 451-457. https://doi.org/10.1007/s00221-002-1319-y

West, W. C., \& Holcomb, P. J. (2002). Event-related potentials during discourse-level semantic integration of complex pictures. Cognitive Brain Research, 13(3), 363-375. https://doi.org/10.1016/ S0926-6410(01)00129-X

Wicha, N. Y. Y., Bates, E. A., Moreno, E. M., \& Kutas, M. (2003a). Potato not Pope: Human brain potentials to gender expectation and agreement in Spanish spoken sentences. Neuroscience Letters, 346(3), 165-168. https://doi.org/10.1016/S0304-3940(03)00599-8

Wicha, N. Y. Y., Moreno, E. M., \& Kutas, M. (2003b). Expecting Gender: An Event Related Brain Potential Study on the Role of Grammatical Gender in Comprehending a Line Drawing Within a Written Sentence in Spanish. Cortex, 39(3), 483-508. https:// doi.org/10.1016/S0010-9452(08)70260-0

Wu, Y. C., \& Coulson, S. (2007). How iconic gestures enhance communication: An ERP study. Brain and Language, 101(3), 234-245. https://doi.org/10.1016/j.bandl.2006.12.003

Wu, Y. C., \& Coulson, S. (2011). Are depictive gestures like pictures? Commonalities and differences in semantic processing. Brain and Language, 119(3), 184-195. https://doi.org/10.1016/j.bandl. 2011.07.002

Yan, S., Kuperberg, G. R., \& Jaeger, T. F. (2017). Prediction (Or Not) During Language Processing. A Commentary On Nieuwland et al. (2017) And Delong et al. (2005). BioRxiv, 143750. https:// doi.org/10.1101/143750

Yano, T. (1995). An event-related potential study of the effects of semantic deviations: An application of a method of sequential-part presentation. Perceptual and Motor Skills, 81(3 Pt 2), 1091-1098. https:// doi.org/10.2466/pms.1995.81.3f.1091

Yi, A., Chen, Z., Chang, Y., Wang, H., \& Wu, L. (2018). Electrophysiological evidence of language switching for bidialectals. NeuroReport, 29(3), 181-190. https://doi.org/10.1097/WNR.0000000000000950

Yovel, G., \& Paller, K. A. (2004). The neural basis of the butcher-on-the-bus phenomenon: When a face seems familiar but is not remembered. NeuroImage, 21(2), 789-800. https://doi.org/10.1016/j.neuroimage. 2003.09.034

Yum, Y. N., Holcomb, P. J., \& Grainger, J. (2011). Words and pictures: An electrophysiological investigation of domain specific processing in native Chinese and English speakers. Neuropsychologia, 49(7), 1910-1922. https://doi.org/10.1016/j.neuropsychologia. 2011.03.018

Zani, A., Marsili, G., Senerchia, A., Orlandi, A., Citron, F. M. M., Rizzi, E., \& Proverbio, A. M. (2015). ERP signs of categorical and supra-categorical processing of visual information. Biological Psychology, 104, 90-107. https://doi.org/10.1016/j.biopsycho. 2014.11.012

Zhang, X., Li, T., \& Zhou, X. (2008). Brain responses to facial expressions by adults with different attachment-orientations. NeuroReport, 19(4), 437-441. https://doi.org/10.1097/WNR.0b013e3282f55728 
Zhou, H., Fan, S., Guo, J., Ma, X., Yan, J., Qin, Y., \& Zhong, N. (2015). Visual Object Categorization from Whole to Fine: Evidence from ERP. In H. Guo, Y and Friston, $\mathrm{K}$ and Faisal, A and Hill, S and Peng (Ed.), Brain Informatics and Health. BIH 2015. Lecture Notes in Computer Science 9250, 325-334. Springer. https://doi. org/10.1007/978-3-319-23344-4_32
Publisher's Note Springer Nature remains neutral with regard to jurisdictional claims in published maps and institutional affiliations. 